\title{
Building Features in Schools That Influence Academic Performance
}

\author{
Sogol Salary ${ }^{1}$, Lisa Holliday ${ }^{1}$, Marguerite Keesee ${ }^{2}$ and Hans-Peter Wachter ${ }^{3}$ \\ 1. Haskell and Irene Lemon School of Construction Science, University of Oklahoma, Norman 73019, USA \\ 2. Center for Spatial Analysis, University of Oklahoma, Norman 73019, USA \\ 3. College of Visual Arts and Design, University of North Texas, Denton 76201, USA
}

\begin{abstract}
School decision makers are faced with a great many decisions when considering a school renovation or new school building. All stakeholders want a building that is safe and provides an optimal learning environment. However, it is often difficult to know which building features will have the greatest effect on student learning. Because of a limited understanding of the relationship between individual building features and student learning, researchers at the University of Oklahoma hope to explore how building components influence student and teacher performance. This paper explores the importance of school building features that can be designed and changed during a renovation project. The hope is to one day determine which features have the greatest impact on student test scores. The research team believes that although it is difficult to find the exact relationship between each building features and student outcomes with one study, if multiple users repeat the same or similar studies, hopefully we will one day know the effect of these building features. In order to develop feature building users survey and physical assessment tools, it was necessary for investigators to develop a list of important building features and their associated definitions in layman terms. This was accomplished through utilization and conducting of a CAB (community advisory board) and subject matter expert materials. In addition, previous research relating to different school building features and their associations with student performance were reviewed. To define and narrow the list the researchers, community educational, and building professionals rated based on their professional experience, how directly related each feature is to student performance. The building feature list serves as a starting point to determine which features should be analyzed in a later phase of the project. It is hoped that resulting tools based on the work of this project can be used by school decision-makers and researchers to access building features that have been identified through research as being important for student and teacher performance.
\end{abstract}

Key words: School building features, student performance, school facilities, school architecture.

\section{Introduction}

As discussed in Marshall [1], in Oklahoma tornados have resulted in injury and death to many, as well as significant physical damage to buildings. During the last decade, and especially after the 2013 tornado in Moore, Oklahoma, natural disasters have raised concerns over the safety of school facilities. Safety is of course a primary concern, but decision makers should know if they are trading safety for other important building features that impact student

Corresponding author: Sogol Salary, Ph.D. student, research fields: school building renovation, renovation scheduling and management, and building components in school buildings. performance. As a result of the recent tornados, safety in school design has become the fundamental design parameter for new construction and renovation in order to guarantee safe-learning environments for students and teachers. When a building structure is hardened to serve also as a storm shelter the interior and the exterior school facilities are changed. This paper identifies building features believed to be important in student performance. If this study is replicated by multiple groups, the hope is to one day determine the significance of each building feature in student learning from the perspective of researchers and community educational and building professionals. 


\subsection{Importance}

Previous research has demonstrated that student and teacher performance is associated with conditions of the physical environment [2]. When hardening building structures, a trade-off between safety, building features, and interior condition can result. However, the complex nature of this relationship is not well understood. Therefore, exploring the role of buildings and their features is important. To better serve their communities, it is important that design and school professionals gain a clearer understanding of this complex relationship so that school buildings can be created with effectively balancing and prioritizing between safety features, other building features, and student performance.

Goals and Purposes. The goal is to create a list of building features that are believed to affect student performance which can be tested as variables for statistical associations with student test scores. Among the building features list, some components have been previously studied by other researchers while other components have not. The feature list is created without discipline specific jargon in order that lay persons could easily understand and implement the list so that decision making tool develop could be easily used and therefore broadly adopted by the school administrators and public users.

One of the desired outcomes for this project is the development of a simple to use assessment methodology that can be adopted by administrators to assess building needs and increase school performance. Objective assessments using architects and other professionals have also been used numerous times in past studies. Many previous researchers have used surveys and assessments comprised of Likert scale based measures to study room user perceptions of building features such as lighting and acoustic. However, since this time, equipment to register light, sound, and temperature have become more affordable. Thus, researchers employed a mixed methods research design which incorporated the collection of both perception and objective assessments of building features.

\subsection{Methodology}

The OU (University of Oklahoma), Construction Science Division received a grant from the U.S. EPA (Environmental Protection Agency) to study how new construction, renovation and structural hardening affect school interiors, sustainability, IAQ (Indoor Air Quality) and ultimately their impact on student performance. The first phase of the project utilized the following strategies to compile a list of school building features to be investigated.

Researchers reviewed existing literature to identify important building features (e.g., windows, floors, materials, etc.) and factors (e.g., lighting, acoustics, thermal comfort, interior design and aesthetics) that have an impact on student performance and to what degree these components/features influence student outcomes. Then, researchers conduct 14 interviews of school decision leaders, principals, nurses, teachers, and school board members to complement the findings from the research literature and identify essential building features according to occupants and other constituent groups associated with public preK-12 (pre-kindergarten through 12th grade) school facilitates.

In order to ensure that the work is grounded in experience and is useful to school building users, a CAB (Community Advisory Board) which was a representative of different stakeholder groups including teachers, parents, students, and school board members, was established. The CAB provided feedback relating to key building features in public school buildings and aided in the development of a list of these key features to be included in tests of association with student achievement. In addition a local design-build firm was hired to be a part of the research team and a member of the CAB. They provided professional and technical expertise on the public school district decision-making processes and 
important building features in school design.

Finally, the research team $(n=13)$ and $\mathrm{CAB}$ members $(n=18)$ rated the importance of each identified building feature. The resulting list was extensive resulting in the narrowing down of the list to those features believe to have the most direct effects on student performance due to school sample size limitations. The feature list was narrowed using the subjective valuation based on the field experience research team and $\mathrm{CAB}$ members. The relationship between the building features and student performance will be tested statistically later in the research project. The conclusion of all collaborations, discussion, reviews, and researchers resulted in the categorization of building features into five building concept groups. Each concept group is presented below and includes a discussion regarding related items, components, characteristics and standards.

\section{Lighting Features}

\subsection{Lighting Literature Review}

Earthman [3] identifies lighting as one of the most studied building components in classroom environments with natural light having a positive impact on student achievement. For Earthman, light quality and quantity are fundamental elements of classroom lighting. The quality of light generally refers to natural or artificial light with artificial light consisting of incandescent, florescent, or LED (light emitting diode). The Earthman's report [3] discusses the benefits of fluorescent lighting in the classroom and suggests that fluorescent lighting may result in higher student performance gains than schools without this type lighting. This study did not discuss the effect of incandescent and LED lighting on student performance.

Also, quantity of light is generally measured using standards for each specific task. The light intensity of natural and artificial light together forms the necessary quantity of illuminance. In general classroom lighting should be within the range of 200 to 500 Lux (18.5 to
46.5 foot candle (fc)) for writing, lecturing, and demonstrating activities [4], as established by the IESNA (Illuminating Engineering Society of North America). Moreover, the Society of Light and Lighting [5] summarized the minimum required light level for functional areas in classrooms and specified the range between 300 to 500 lux (30-46.5 fc), as described in table ${ }^{1}$.

Students exposed to natural light in schools performed 20 percent better than students in classrooms without natural lighting [3]. Moreover, Heschong [6] found a statistically significant relationship between daylighting provided by windows and skylights and students performance. The study shows that:

"Students with the most daylighting in their classrooms progressed 20 to 26 percent faster in one year than those with the least. Similarly, students in classrooms with large window area were found to progress 15 to 23 percent faster than those with the least and finally, students that had well-designed skylight, skylight with diffusing lenses, in their room improves 19 to 20 percent faster than those students without a skylight".

Additionally, Heschong identified statistically significant effects of daylight on human behavior as measured by the standardized test scores for elementary school students. She concluded that providing most window areas or daylighting for classrooms will help students to achieve 7 to 18 percent higher test scores compared to students who are in classrooms with least provided window areas or daylighting [6].

A relationship between windows, lighting control systems and student achievement was investigated by Nicklas and Bailey [7] in a study of North Carolina elementary and middle schools. They analyzed the impact of full-spectrum light on student test scores. The study also included features such as roof monitoring,

\footnotetext{
${ }^{1}$ The table was reproduced under the permission of CIBSE publication, London, UK. The permission was received on August 10th 2017.
} 
Table 1 Summary of minimum recommended illumination level for classroom.

\begin{tabular}{llll}
\hline Room & Description & Min $(\mathrm{fc})$ & Min (lux) \\
\hline Classroom & Lecture hall & 30 & 300 \\
Classroom & Art room & 46.5 & 500 \\
Classroom & Science laboratory & 46.5 & 500 \\
Library & - & 30 & 300 \\
Classroom & Music room & 30 & 300 \\
Classroom & IT room & 30 & 300 \\
Classroom & Classroom used for adult education & 46.5 & 500 \\
\hline
\end{tabular}

baffles, light sensors, and the orientation of the building. Results of the study showed that students who attended day lit schools and experienced longer-term impact outperformed the students who were attending non day lit schools by 5 to 14 percent. Day lit schools were defined as schools with $70 \mathrm{fc}$ of natural light for more than 60 percent of the time the room was occupied [7].

Further results from a study conducted by Plympton, Conway and Epstein [8], suggest that not only student performance but their overall well-being may be improved by using daylighting in schools. Grangaard [9] examined the effect of color and light on the learning of eleven 6-years-old students. The study involved a standard classroom with cool-white fluorescent light with white walls, and a modified classroom with full-spectrum Duro-test Vita-lite light with blue walls. Children were videotaped and their blood pressure was monitored to measure off-task behavior. Results of the study show that there is a 22 percent decrease in off-task behaviors for students who studied in a standard classroom compared to students monitored in a modified classroom. Grangaard argues that off-task behaviors are an indicator of a lack of engagement in learning such as looking outside the windows, squirming in the seat and talking with other students. Moreover, the study found that the students' average blood pressure in the modified classroom was nine percent lower compared to students' average blood pressure in the standard classroom. Grangaard [9] suggests the changes in student actions and behavior may be a result of a reaction between the participants' blood pressure and lighting color.

\subsection{Lighting Features and Results}

The research team defined the overall concept of lighting as a combination of natural and artificial light that illuminates study surfaces and creates specific conditions in a space or room. For specific lighting features, a list of the features and their non-technical definitions is provided in Fig. 1 (see Appendix A for the complete building features list and definitions, measurements and units of each lighting component).

\subsubsection{Lighting Features}

Industry lighting standards have been established for levels of illumination by specific tasks or uses. It is further indicated in the standards that natural daylight (day-lit school designs) with uniform light distribution is ideal.

Lighting issues with hardened structures. In various schools, hardened structures or storm shelters are built and used for classrooms and gyms. Sometimes, students spend a great portion of their time learning and/or testing in these hardened environments. Therefore, providing adequate natural light in designed safe areas is fundamental but, in many schools, lighting in hardened structures is expensive and therefore overlooked. In addition to providing the safest area, builders tend to increase the amount of hardened material and fail to include windows and other sources of natural light in safe rooms in order to reduce the construction costs. This illustrates one of the potential trade-offs between safety and healthy learning interiors. 


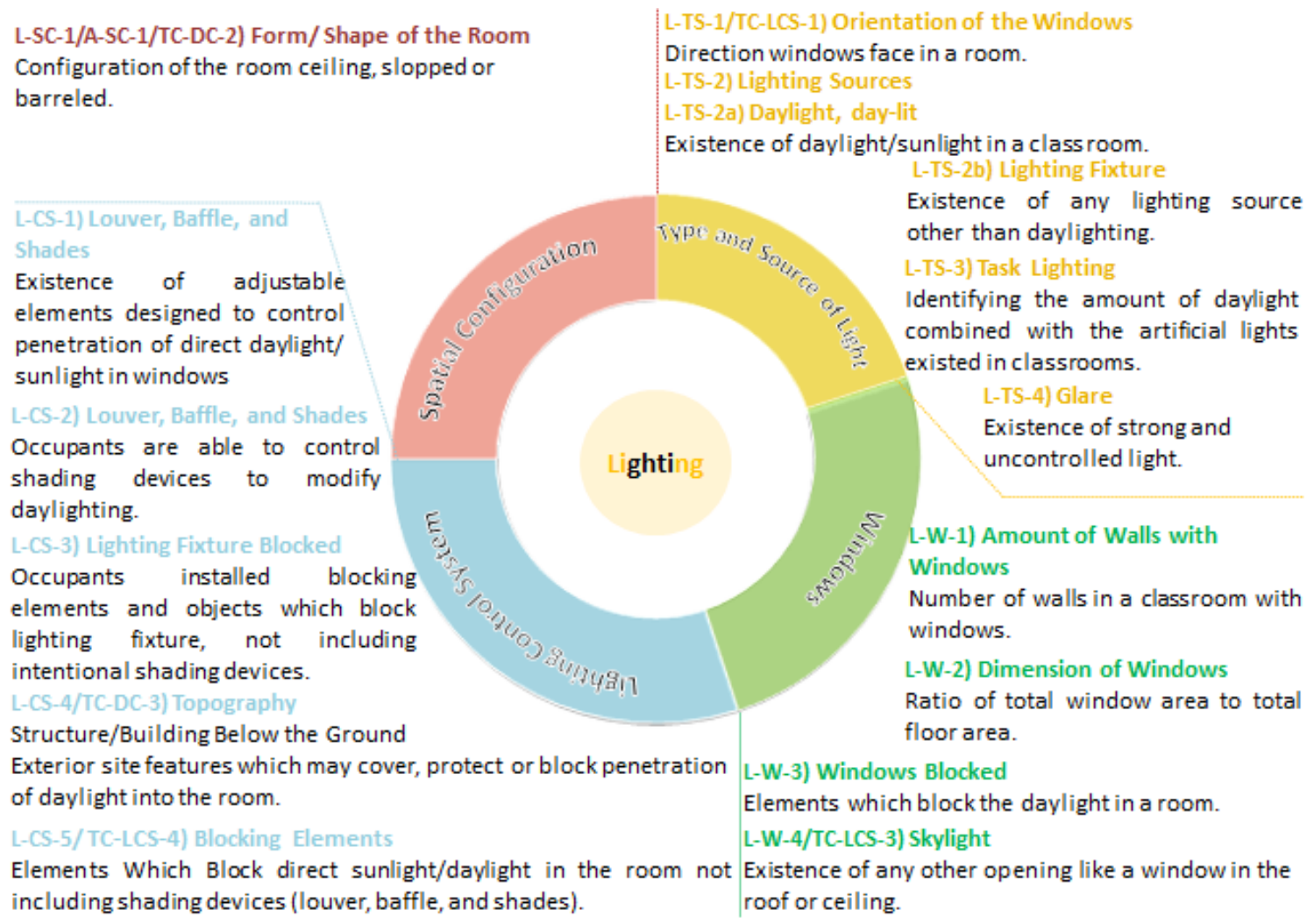

Fig. 1 Lighting features.

\subsection{Lighting Feature Ratings}

Researchers rated each of the collaboratively identified building features with respect to the predicted relationship between features and the measure of student performance used. Specifically, as shown in Table 2, each feature was categorized as being directly, indirectly or weakly/not significantly related to the final outcome measure in this study. Features that were rated as directly related based on professional experience were measured in building assessments.

\section{Acoustic Features}

\subsection{Acoustic Literature Review}

A study done by Earthman [3] shows that student's achievements are negatively affected by high noise levels produced both inside and outside of the classroom. When considering acoustic conditions in the built environment, the key considerations are the generation, transmission and reception of sound [10]. One factor related to room acoustics that affects speech intelligibility is the background noise level [11]. In accordance with the ANSI S12.60, standard on classroom acoustics, the maximum unoccupied background noise level for classrooms should not exceed 35 decibel (dB) [12]. However, Ronsse and Wang [13] indicate that research is needed to determine if meeting this standard is associated with student achievement.

Malik and Farid [14] explained that audio reverberation is persistence of sound, according to different reflections from multiple sources in a room. Excess reverberation of noise is the main variable responsible for unsatisfactory acoustic conditions [15]. According to Sabine's equation that calculates the reverberation time in a room, an indirect relationship between reverberation time and absorption coefficient level exists [16]. Considering this relation, improving the absorption level of materials and spaces will decrease 
Table 2 Predicted association of CAB identified lighting features to student achievement.

\begin{tabular}{|c|c|c|c|c|}
\hline \multirow[b]{2}{*}{ Building feature } & \multirow[b]{2}{*}{ Category } & \multicolumn{3}{|c|}{ Relationship with student outcomes } \\
\hline & & Direct & $\begin{array}{l}\text { Indirect/moderate } \\
\text { relationship }\end{array}$ & $\begin{array}{l}\text { Week/no significant } \\
\text { relationship }\end{array}$ \\
\hline \multirow{5}{*}{$\begin{array}{l}\text { Type and source of } \\
\text { lighting }\end{array}$} & Orientation of the windows (L-TS-1/TC-LCS-1) & & $\mathrm{x}$ & \\
\hline & Lighting source 3/day light, day-lit (L-TS-2a) & $\mathrm{x}$ & & \\
\hline & Lighting source/lighting fixtures (L-TS-2b) & $\mathrm{x}$ & & \\
\hline & Task of lighting (L-TS-3) & $\mathrm{x}$ & & \\
\hline & Glare (L-TS-4) & $\mathrm{x}$ & & \\
\hline \multirow{4}{*}{ Windows } & Amount of walls with windows (L-W-1) & $\mathrm{x}$ & & \\
\hline & Dimension of windows (L-W-2) & $\mathrm{x}$ & & \\
\hline & Windows blocked (L-W-3) & $\mathrm{x}$ & & \\
\hline & Skylight (L-W-4/ TC-LCS-3) & $\mathrm{x}$ & & \\
\hline \multirow{5}{*}{ Lighting control system } & Louver, baffle, and shades (L-CS-1) & $\mathrm{x}$ & & \\
\hline & Louver, baffle, and shades (L-CS-2) & $\mathrm{x}$ & & \\
\hline & Lighting fixture blocked (L-CS-3) & & $\mathrm{x}$ & \\
\hline & Topography (L-CS-4/TC-DC-3) & & $\mathrm{x}$ & \\
\hline & Blocking elements (L-CS-5/TC-LCS-4) & & $\mathrm{x}$ & \\
\hline Spatial configuration & $\begin{array}{l}\text { Form/shape of the room } \\
\text { (L-SC-1/A-SC-1/TC-DC-2) }\end{array}$ & & & $\mathrm{x}$ \\
\hline
\end{tabular}

the reverberation level in a space. Consequently, the sound absorption coefficient for various materials used in ceilings, walls, and floors is particularly important to consider when attempting to improve classroom acoustics specially in relation to reverberation levels [17].

According to ANSI Standard, S12.60, excessive background noise or reverberation interferes with speech communication and thus presents an acoustical impediment to learning [12]. Moreover, exposure to background noise, is associated with higher level of annoyance with perceived stress and poor reading comprehension in students [18]. According to Moslemi Haghighi, Chiao and Bin Mohd Jusan [19], there is a relationship between materials used in the room, their absorptive and reflective features and the listening and speech in classrooms. Absorptive and reflective materials are necessary in a classroom because an uncontrolled amount of absorption and reflection of sounds drastically interferes with students' listening processes. As decreases in the absorption level associated with increases in reverberation time, speech perception tends to worsen in classrooms with low level absorbing materials. The preferred reverberation range in classrooms is between $0.6 \mathrm{sec}$ and $0.7 \mathrm{sec}$ depending on room size [12].

In addition to reverberation, background noise also interferes with speech communication and thus presents an acoustical impediment to learning [12]. As reviewed by Knecht et al. [20], three different sources of background noise can be existed that may produce undesired sound in classrooms:

- sounds generated outside of the building such as motor vehicle traffic, playground noise;

- pass-through noise that is generated in adjacent rooms and corridors (such as hallway, gymnasium, and cafeteria);

- sounds generated by the building itself (i.e. HVAC (heating, ventilation, and air conditioning) units, computers, electrical appliances, and ductborne HVAC noise) [20].

Research conducted by Maxwell and Evans [21] found that students of a school located near an airport had 20 percent lower test scores compared to schools located in zones more distant from the airport. These reviews suggest that high levels of background noise and the use of aurally reflective materials in learning 
environments are likely to degrade the intelligibility of speech, negatively affecting student achievement and teacher performance.

\subsection{Acoustics Features and Results}

The $\mathrm{CAB}$ members identified adequate acoustic environments as an important building condition needed for student learning so that they can communicate easily without raising their voice. The $\mathrm{CAB}$ members commented on the design variables presented by researchers: (1) adjacency to spaces; (2) configuration of functional areas; (3) background noise as a distractor; (4) unconventional design materials; (5) room layout that affects the acoustic environment in school facilities. The research team developed the list of key acoustic topics provided below from the CAB's input. Fig. 2 provides a list of key acoustical features and their non-technical definition (see Appendix A for the complete building features list and definitions, measurements and units of each acoustic component).

\subsubsection{Acoustic Features}

The research team defined acoustics as the total effect of sound and its generation, transmission and reception in open and enclosed spaces. They argue that acoustical environment should provide for the transmission of clear speech and diminish the effect of background noise or any additional distracting noises.

Adjacency to spaces. The team further clarified that teachers, principals, and students identified the existence of a clear path between spaces such as classroom and bathroom, administration and school entrance, and gym and playground/sports fields as a beneficial consideration in school buildings. In many cases, long and complicated paths between spaces increase noise levels at peak hours especially when a large group of students travels through the building which can disrupt adjacent activities and affect the acoustical environment, student engagement, and learning activities.
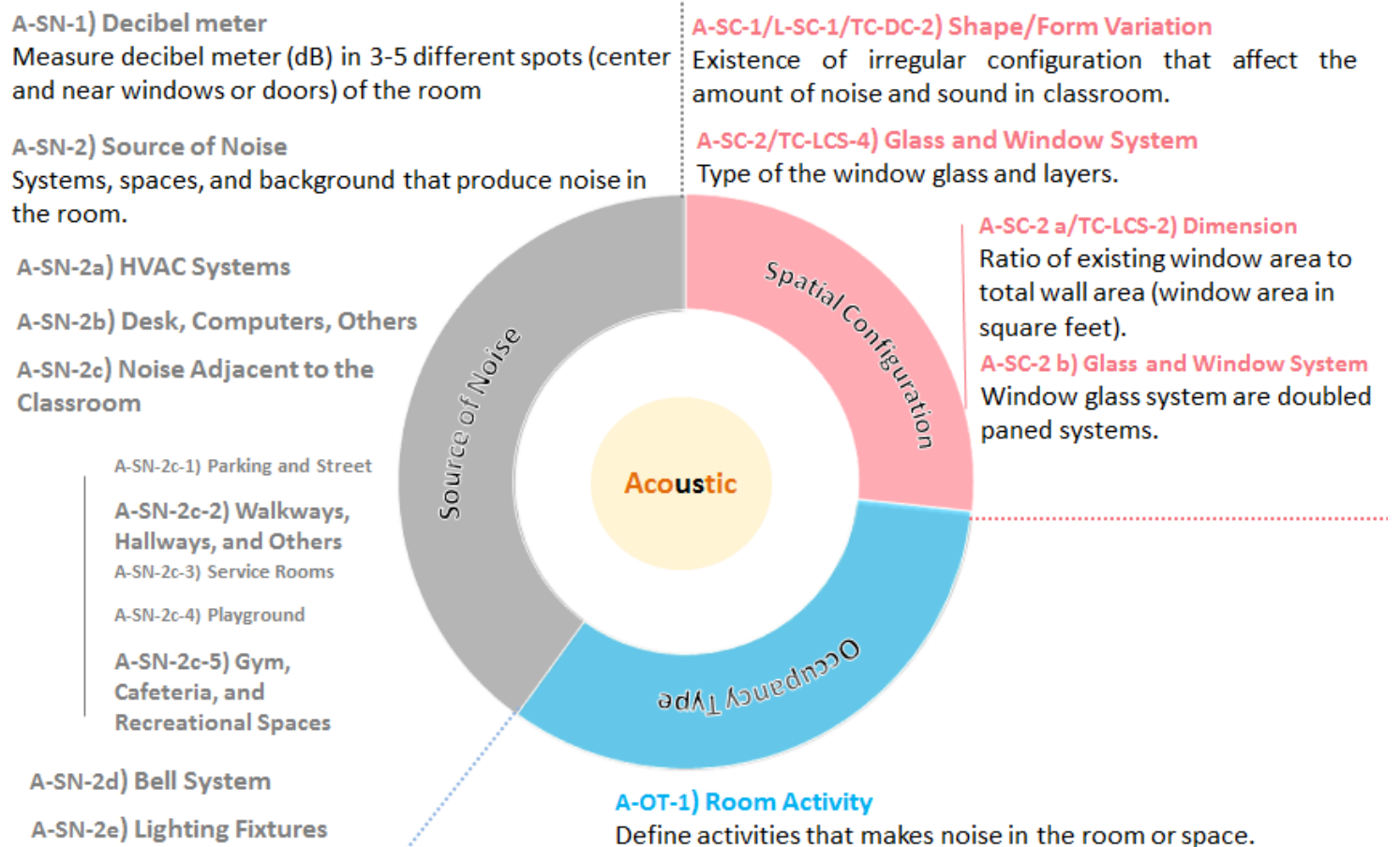

A-OT-1) Room Activity

Define activities that makes noise in the room or space.

A-OT-2) Population Density

Define Average number of people that use the space and contribute to noise.

Fig. 2 Acoustic features. 
Configuration and functional areas. The length and configuration of hallways, and the excessive acoustic level produced by these spaces especially during peak hours is another feature that can affect the attention and performance of students and teachers in classrooms, as suggested by the CAB members. This is a common problem noted in the field of architecture where long and stretch hallways with reflective materials produce poor acoustic environments. The result is a space with a more aggressive and chaotic environment. In addition, the existence of distracting noise features such as bell system which is a signal for the beginning and ending of classes/activities can produce disruption and can be excessively loud. Additionally, bell systems can sound several times per hour and this can create a disruption in learning activities.

Distracting noises. Finally, an unconventional school building design is another potentially problematic acoustic related component identified by the research team. Alternative design principles are used in some school buildings in order to achieve sustainable facilities and dynamic environments but may affect acoustics. Some schools are using operable windows for better ventilation and airflow which also produce an inlet for exterior noises. Moreover, using movable partitions in school buildings for creating a more dynamic, flexible and integrated space can result in excessive interrupting noises. Lightweight materials used to build the partitions may not effectively isolate sound from adjacent rooms. In addition, different type of activities that can be done in study rooms will change acoustic condition and may result in dissipating sound through a building.

\subsection{Acoustics Feature Ratings}

In the analysis of acoustic building features, the features were rated based on the predicted effect on student performance. This was done to identify key features that would be measured in building assessments. Table 3 displays the team's rating of specific acoustical building elements to student performance.

\section{Thermal Comfort Features}

\subsection{Thermal Comfort Literature Review}

Findings from previous research indicate that the thermal environment of a classroom is an important factor in student well-being, performance, and attendance [2, 22-25]. Elements associated with the thermal environment include IEQ (indoor environmental quality), temperature, $\mathrm{RH}$ (relative humidity) and IAQ [24]. Building and classroom temperature was a frequent issue discussed by $\mathrm{CAB}$ members and individuals participating in the interview

Table 3 Predicted association of CAB identified acoustic features to student achievement.

\begin{tabular}{|l|l|l|l|l|}
\hline \multirow{3}{*}{ Building feature } & \multirow{2}{*}{ Category } & \multicolumn{2}{|c|}{ Relationship with student outcomes } \\
\cline { 3 - 5 } & & Direct & $\begin{array}{l}\text { Indirect/moderate } \\
\text { relationship }\end{array}$ & $\begin{array}{l}\text { Week/no significant } \\
\text { relationship }\end{array}$ \\
\hline \multirow{5}{*}{ Source of noise } & Decibel meter (A-SN-1) & $\mathrm{x}$ & & \\
\cline { 2 - 5 } & Source of noise/HVAC systems (A-SN-2a) & & $\mathrm{x}$ & \\
\cline { 2 - 5 } & Source of noise/desk, computers, others (A-SN-2b) & & $\mathrm{x}$ & \\
\cline { 2 - 5 } & $\begin{array}{l}\text { Source of noise/noise adjacent to the classroom } \\
\text { (A-SN-2c) }\end{array}$ & & $\mathrm{x}$ & \\
\hline \multirow{5}{*}{ Spatial configuration } & Shape/form variation (A-SC-1/L-SC-1/TC-DC-2) & & $\mathrm{x}$ & \\
\cline { 2 - 5 } & Glass and window system (A-SC-2/TC-LCS-4) & & $\mathrm{x}$ & \\
\cline { 2 - 5 } & Dimension (A-SC-2 a/TC-LCS-2) & & $\mathrm{x}$ & \\
\cline { 2 - 5 } Occupancy type & Glass and window system (A-SC-2 b) & & $\mathrm{x}$ & \\
\cline { 2 - 5 } & Room activity (A-OT-1) & Population density (A-OT-2) & & \\
\hline
\end{tabular}


component of the OKHS (Oklahoma Health Schools) study. Given the frequency of this complaint heard at the beginning of this study, as well as the multitudes of factors that influence human perception of comfort, it is not surprising that researchers have not be able to establish a consistent optimal temperature range or set of ranges for building environments. For now, Tom [25] suggests that trends in the research support a range of temperatures roughly between $72{ }^{\circ} \mathrm{F}$ and $77^{\circ} \mathrm{F}$ for workplace environments and slightly lower range for classroom with needed temperature varying by the type of activities being performed in the space.

For classrooms in general, a 2010 report from the New York State Department of Health established a standard range of $65^{\circ} \mathrm{F}$ to $75^{\circ} \mathrm{F}$ [26]. Moreover, a study conducted by researchers at the University of Denmark further shows that math and reading performance improved by 28 and 24 percent when classroom temperatures were decreased from $76^{\circ} \mathrm{F}$ to $67{ }^{\circ} \mathrm{F}$ [27]. Also, Wargochki and Wyon [28] found that reducing air temperature in classrooms that had moderately elevated temperatures improves academic performance of children. This study shows that the optimal room temperature for student performance was achieved at $68^{\circ} \mathrm{F}$.

Additionally, the type of building materials used influences thermal comfort [29-31]. Specifically, Wafi and Ismail [29] found that different building materials (e.g. brick, concrete, and timber) have effects on the overall thermal comfort. For instance, reflective materials provide benefits in term of thermal comfort, because these materials, according to their optical properties, stay cooler than standard materials [30]. Moreover, the color of surfaces can increase or decrease surface temperatures by affecting the albedo of material, so that darker surfaces absorb light and have lower albedo, while lighter surfaces reflect more light and have higher albedo [30]. Thus, the surface color of materials used can affect the thermal comfort in a space.

\subsection{Thermal Features and Results}

In the State of Oklahoma wide fluctuations in outside temperatures between and within seasons require the use of functional and efficient HVAC systems. However, the age of the school building and the air conditioning units within the buildings may not be able to effectively support the desired temperature range. In addition, most of the schools have limited airflow, which degrade interior conditions and air quality. The CAB identified three main variables and features that impact thermal comfort including buildings with outdated heating and cooling design strategies, manual control of indoor room temperatures, and cultural perceptions of thermal comfort. Although the concept of thermal comfort is typically comprised of numerous aspects, the definition of thermal comfort used in this study focuses on temperature and humidity. Fig. 3 provides a list of key thermal comfort features and their non-technical definition (see Appendix A for the complete building features list and definitions, measurements with units of each acoustic component).

\subsubsection{Thermal Features}

The team defined thermal comfort as the combination of air temperature and mean radiant temperature that people find thermally acceptable. For a given value of humidity, air speed, metabolic rate, and clothing insulation, a comfort zone may be determined. The comfort zone is defined in terms of the range of operative temperature that provides acceptable thermal environmental condition. For the purpose of the OKHS study, the comfort zone of $68^{\circ} \mathrm{F}$ to $77^{\circ} \mathrm{F}$ which is recommended by Refs. [25, 26, 32] is being adopted.

Key thermal factors identified by the CAB members included issues associated with the age of school buildings, manual control of room temperatures, and cultural perceptions of thermal 


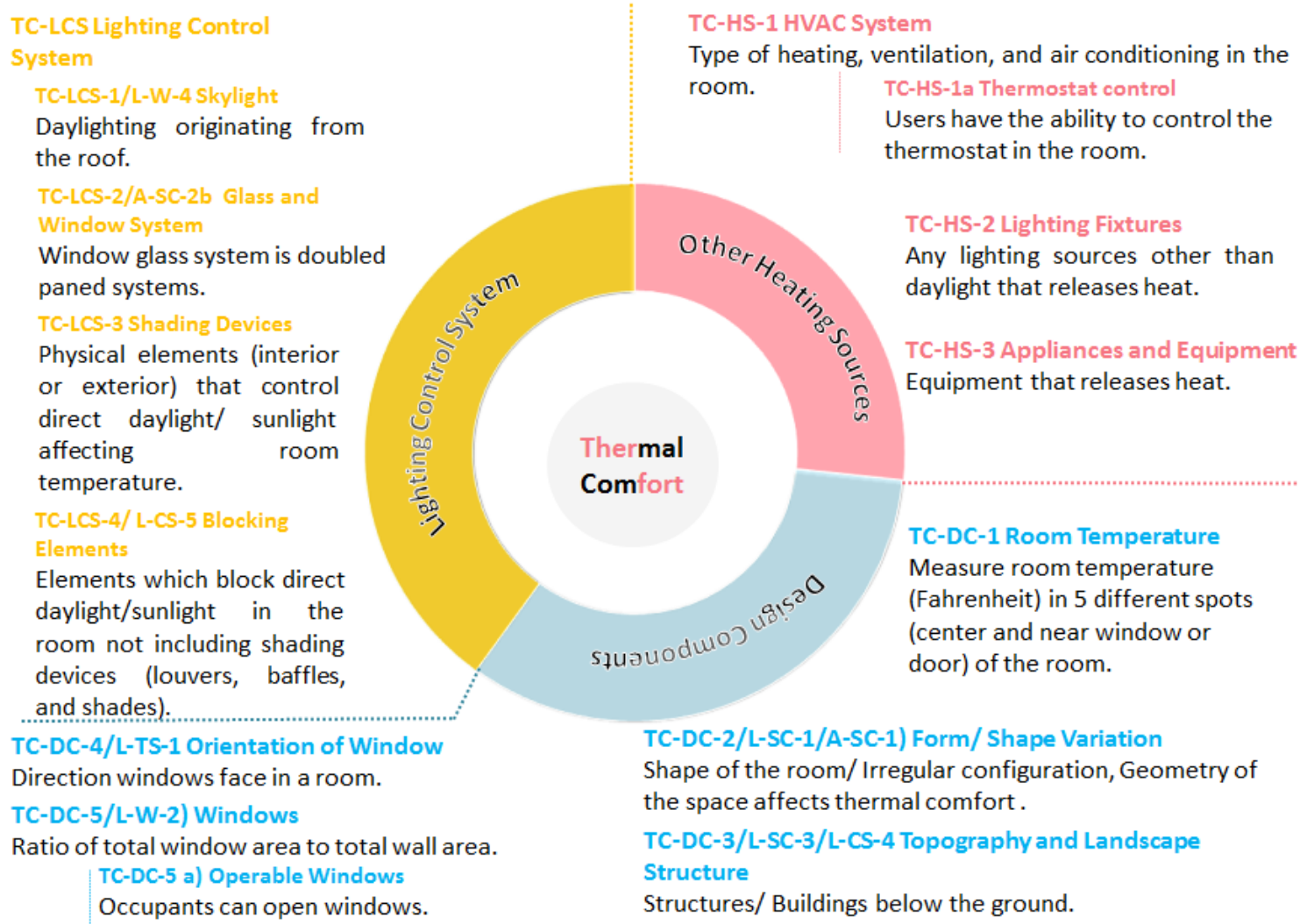

Fig. 3 Thermal comfort features.

comfort. The research team synthesized these mentioned key thermal comfort topics based on the Community Advisory Board's input.

Issues with old thermal comfort design. School buildings still in use by Oklahoma City public schools were mainly built between 1917 and 1967 (76\%). According to our key informants, at that time, buildings were designed with two principles in mind; heating systems to keep the building warm in winter and natural airflow with thick walls and high ceilings to keep spaces cool during the summer. Thus, in old building designs, the lack of air-conditioning was evident and several design strategies (passive systems) such as cross ventilation, stack effect, operable windows and orientation of the building, were used to control thermal comfort and improve interior air quality. However, sometime during the 1990's, HVAC systems were installed in each school. The new HVAC installation improved the built environment along with the thermal comfort, but the lack of proper maintenance degraded the systems. Thus, some schools possibly experienced lower air quality conditions and thermal comfort. Brager et al. [33] explained that providing central HVAC system instead of natural ventilation that can be provided by operable windows, made occupants not be able to control their environment (similar to laboratory studies). Therefore, the need for passive ventilation systems in order to balance the possible failure of HVAC systems and provide a comfortable environment for students could be necessary.

Manual control of temperature. Since 2000, many schools in Oklahoma have undergone many important renovations such as HVAC systems. One of the goals of the school districts participating in this study, in terms of functionality and systems management, was to install a centralized unit that controls the temperature of all the schools in the district and does not allow for significant manual control. On several occasions, the $\mathrm{CAB}$ members and 
interviewees commented that interior temperature of classrooms can be under $68^{\circ} \mathrm{F}$ or over $80^{\circ} \mathrm{F}$. Even though the district controls the temperature, it is possible that the new system may not be controlling the temperature optimally at all locations. Teachers may have the need to adjust room temperature by \pm 3 ${ }^{\circ} \mathrm{F}$ to support specific learning activities. However, the manual adjustments that are allowed are limited, may not be operable and in some cases do not appear to meet the needs of building users.

Cultural perception of comfort. The population of families being served by the participating school districts is multicultural with Hispanic, African American/Black, Native American, Asian and White students. Researcher suggest that perceptions of thermal comfort or ideal room temperature are subjective and vary by ethnicity, race, age and/or gender [34-36]. Although an important issue and one that will be considered in future analysis for the OKHS project, an in-depth analysis is beyond the scope of this paper.

\subsection{Thermal Comfort Features Ratings}

Features related to the thermal comfort were rated based on hypothesized direct, indirect, or no significant effects on student performance and final outcome measures, as shown in Table 4. The thermal comfort rating was done to identify key features that should be measured in building assessments.

Collaboratively with the $\mathrm{CAB}$, the research team identified HVAC systems, the age of the building, and last interior renovations as influential variables of thermal comfort. Additionally, the relationship between sunlight, orientation of the building and heat gain may indirectly affect interior conditions and thermal comfort. Further, the materials used may affect the temperature of a space indirectly.

\section{Interior Design Features}

\subsection{Interior Design Literature Review}

In order for schools to address interior design challenges in a manner that provides effective support for student learning, the interior design of school buildings needs to safely and effectively manage the movement and behavior of students, create flexible classrooms that can easily be reconfigured to support specialty programs, rapidly evolving pedagogy and technology, provide a safe haven for students and staff against numerous natural and human precipitated

Table 4 Predicted association of CAB identified thermal comfort features to student achievement.

\begin{tabular}{|c|c|c|c|c|}
\hline \multirow[b]{2}{*}{ Building feature } & \multirow[b]{2}{*}{ Category } & \multicolumn{3}{|c|}{ Relationship with student outcomes } \\
\hline & & Direct & $\begin{array}{l}\text { Indirect/moderate } \\
\text { relationship }\end{array}$ & $\begin{array}{l}\text { Week/no significant } \\
\text { relationship }\end{array}$ \\
\hline \multirow{6}{*}{ Design components } & Room temperature (TC-DC-1) & $\mathrm{x}$ & & \\
\hline & Form/shape variation (TC-DC-2/L-SC-1/A-SC-1) & & & $\mathrm{x}$ \\
\hline & $\begin{array}{l}\text { Topography and landscape structure } \\
\text { (TC-DC-3/L-SC-3/L-CS-4) }\end{array}$ & & $\mathrm{x}$ & \\
\hline & Orientation of window (TC-DC-4/L-TS-1) & & $\mathrm{x}$ & \\
\hline & Windows (TC-DC-5/L-W-2) & $\mathrm{x}$ & & \\
\hline & Operable windows (TC-DC-5a) & & $\mathrm{x}$ & \\
\hline \multirow{4}{*}{$\begin{array}{l}\text { Other heating } \\
\text { sources }\end{array}$} & HVAC system (TC-HS-1) & $\mathrm{x}$ & & \\
\hline & Thermostat control (TC-HS-1a) & $\mathrm{x}$ & & \\
\hline & Lighting fixtures (TC-HS-2) & & $\mathrm{x}$ & \\
\hline & Appliances and equipment (TC-HS-3) & & $\mathrm{x}$ & \\
\hline \multirow{4}{*}{$\begin{array}{l}\text { Lighting control } \\
\text { system }\end{array}$} & Skylight (TC-LCS-1/L-W-4) & $\mathrm{x}$ & & \\
\hline & Glass and window system (TC-LCS-2/A-SC-2b) & & $\mathrm{x}$ & \\
\hline & Shading system (TC-LCS-3) & & $\mathrm{x}$ & \\
\hline & Blocking elements (TC-LCS-4) & & $\mathrm{x}$ & \\
\hline
\end{tabular}


disasters, and contribute to efficient public sector spending through the use sustainable interior materials that promote learning, health and long-term usability. Frequently, major capital investments or critical infrastructure projects are deferred to future budget cycles, sometimes for years by school districts, so that limited funds can be spent on new methods, programs, technology, classroom materials and staffing [37-39]. However, research on school building design and conditions indicates that aspects of interior design play an important part in student behaviors, attitudes and achievement [3, 37, 38, 40-44].

In the "Condition of Education 1994" report, Commissioner Elliott, for the National Center for Educational Statistics, asked "Are schools providing a safe and supportive environment so that student energies can be devoted to learning?" [46]. He concluded then that although the nation could celebrate many accomplishments, there were numerous ongoing challenges that had yet to be adequately addressed including the inequality of property tax based funding for school districts, and rising enrollments in general and specifically among children with special needs, English language learners, and the spatial concentration of families living in poverty [46]. Today, school districts still face these same challenges, as well as an aging physical infrastructure and rapid changes in educational technology.

Research conducted by Tanner [47, 48] and Barrett et al. [43, 45], using composite measures of different building features identified several interior design elements that have significant effects on student performance. Measures of design elements used in Tanner studies were from a larger instrument designed for assessing physical learning environments by researchers at the SDPL (University of Georgia's School Design and Planning Laboratory's). Tanner compared student achievement with composite measures of movement and circulation, views of nature and lighting to student achievement for both 3rd and 5th grade students. The study of 3rd graders included measures for instructional neighborhoods and large group meeting places. Statistically significant relationships between the design measures and scores on the ITBS were found for all composite measures $[47,48]$.

Using a multi-level modelling strategy to analyze three levels of data for 751 students in 34 classrooms in seven schools in the UK, Barrett et al. [43] found that six design elements accounted for $73 \%$ of the class level variance associated with student learning rates including color, choice, connection, complexity, flexibility, and light. Generally these findings were supported in a 2015 follow-up study conducted by Barrett et al. on 153 classrooms in the UK. Specifically, the researchers found that $16 \%$ of the variance in individual student performance was explained by seven design elements, four of which fall under the category of interior design in this presentation and include ownership, flexibility, complexity, and color [45].

Another interior design consideration is overcrowding. Since the early 1900's, educators have been concerned with the issue of school overcrowding [49] and its effects on student learning and behavior [50, 51]. Overcrowded schools generally occur when student enrollments exceed building or classroom capacity [52].

Due to common limitations associated with research in Education, the interpretation of research findings is often contentious. However, the state of Tennessee took a rare step and began an experiment on the effect of class size on student achievement entitled Project Star. Project Star was the first of a three phase project that started with the random assignment of kindergarten students and teachers to a small sized classroom with less than 20 students and one teacher, a regular sized Tennessee classroom with one teacher or a regular sized classroom with one teacher and a teacher's aid. Students and teachers participated in the project for four years beginning in 
Kindergarten and continuing through the 3rd grade. Students and teachers would return to regular classrooms and teaching assignments when students in the experimental group began the 4 th grade. Over 6,000 students from 329 classrooms representing 79 schools and 46 districts participated in the project. The study was designed so that differences due populations served, per-pupil expenditures, instructional resources, and composition of school staff were controlled. Given the use or random assignment of both students and teachers, this study is one the few large scale studies in education of its kind which allows to the extent possible causal conclusions to be drawn about the outcomes [53-56].

Results from the study indicate that when compared to students in the other two groups, students who were in the small class sizes had better academic performance during and after the experimental years with fewer classroom disruptions and discipline problems and student in-grade retentions. Interestingly, there was no difference in student outcome and behaviors found between teacher aide supported and regular classrooms. Also, it appears that minority students and those in inner-city schools reaped the greatest benefits that appear to have continued at least through the 7th grade [54, 55]. Finn and Achilles [55] suggests small classes may improve student achievement because of the effect they have on increased student engagement and participation in the classroom. This argument is consistent with early research that found high density environments often caused children to become stressed and exhibit a number of behaviors that were not conducive to learning such as social withdrawal, task inattention, fidgeting, or aggression [37, 40, 57-59].

\subsection{Interior Design Features and Results}

$\mathrm{CAB}$ member discussions supported findings from previous research and agreed that poor spatial distribution with limited circulation and range of movement, and overcrowded classrooms negatively affect student and teacher performance. Also, CAB members acknowledged that school interior design should include ergonomic and age appropriate furniture, easy to clean and maintain surfaces and fabrics, sufficient storage for students and teachers, media and learning resources, display surfaces for student work, and a sufficient number and placement of functional water fountains. Fig. 4 provides a list of key interior design features and their non-technical definition (see Appendix A for the complete building features list and definitions, measurements and units of each acoustic component).

\subsubsection{Interior design features}

Interior design is defined as interior areas, finishes and furnishings that accommodate the safety, well-being and performance of occupants.

Key factors identified during discussions with $\mathrm{CAB}$ members included issues associated with student population growth, need for additional specialty spaces, and the multi-purposing of key spaces. Specifically, CAB discussions highlighted the following:

Student growth versus school classroom area. One of the main concerns of $\mathrm{CAB}$ members and key informants is the lack of classroom space available. For the districts in this study, a large portion of the renovations budgets for each school was allocated for gym, classroom additions, and new schools. However, even with the addition of classrooms and new schools, some areas in the districts are already exceeding the capacity of the recently renovated or built schools due to student population growth. An example, obtained from key informant interviews, was how student population growth exceeds the capacity of one of the High Schools in the largest participating district, even after classrooms where added and renovated. When the decision to renew and build new classrooms was made, in 2004, the school enrollment of the high school was 856 students. The projected capacity for the new addition was to accommodate an additional 249 students. However, when renovation was started in 


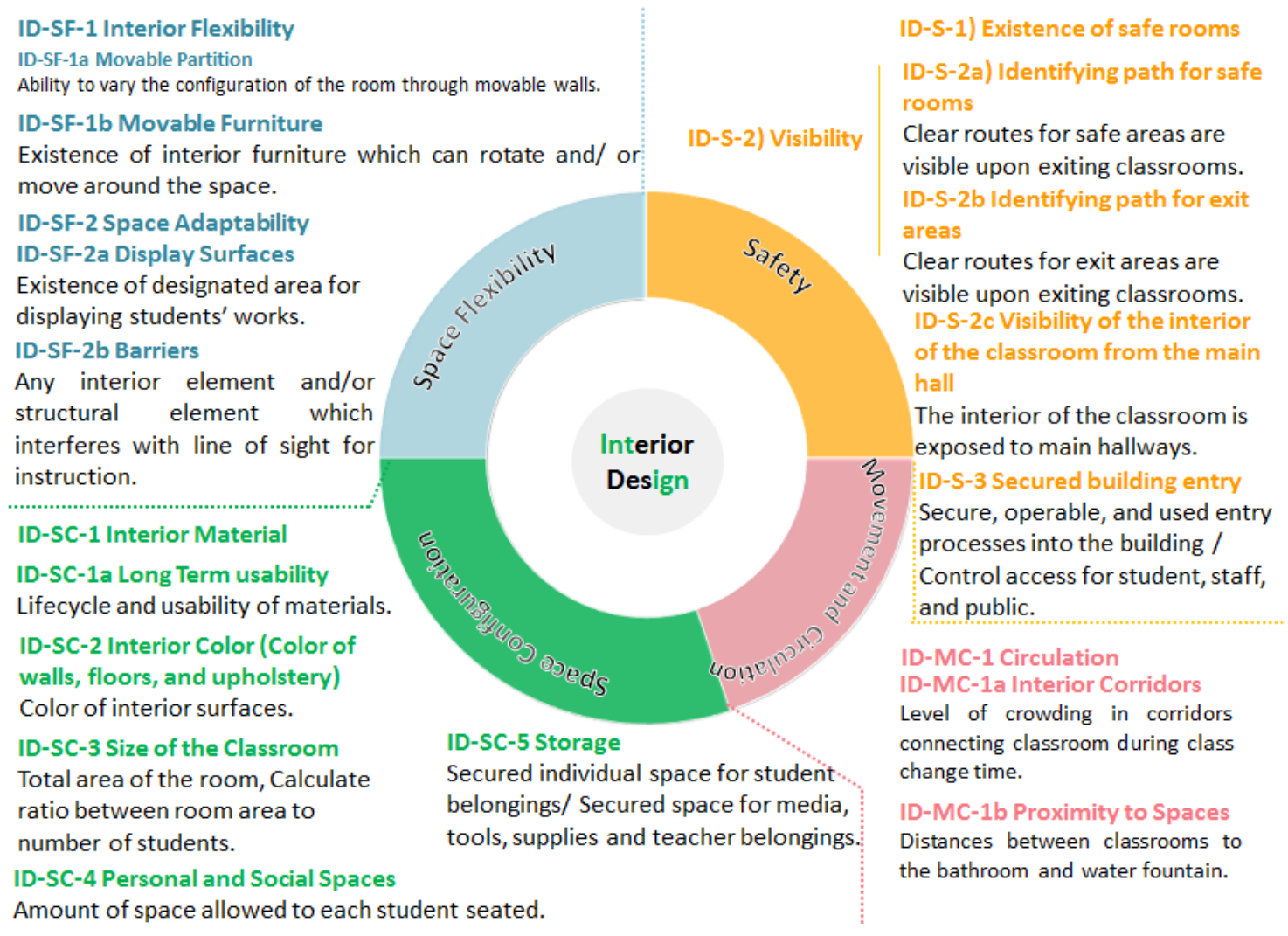

Fig. 4 Interior design features.

2007, the High school's student body had increased over $20 \%$ (around 1100 students). Today, due to continuous student population growth, the school's student population has burgeoned to 1,500 students and continues to grow. As a consequence, classrooms are crowded and approximately 20 teachers are operating as "traveling teachers"-i.e., teachers without permanent classrooms. The issue of accelerated population growth is a concern of schools located elsewhere in the district as well. Accordingly, this example highlights the need for interior and building design to consider population growth and to provide spaces that can more readily accommodate rapidly expanding occupancy rates.

Additional areas to support teaching activities. Study participants argued that providing each teacher with a space that is customizable to enhance teaching methods and learning styles would improve student achievement and teacher pride. Additionally, study participants identified the importance of providing the additional interior space for specialized activities including rooms with desks for tutors, storage areas for daily and seasonal supplies, secure warehouse space, atriums or covered court yards for use as additional learning spaces, teacher collaboration rooms, faculty lunch rooms, counseling rooms and parent support rooms. Study participants argue that these spaces will enhance education, support learning activities and improve student and teacher performance. Additionally, $\mathrm{CAB}$ members emphasized that providing teachers with the right tools and spaces would improve their performance and sense of belonging with the institution and consequently, student achievement would be positively affected.

Multi-purposing of key spaces (gym-cafeteria). Most schools have either a limited budget or limited area to build facilities. A solution to both problems adopted by one of the participating districts was to create multi-purpose spaces. The spaces needed for 
the gymnasium, auditorium and cafeteria in elementary schools were combined to create a space referred to by some of our key informants as gyma-cafe-toriums. The successful creation of such a space requires the right use of materials to support all three activities and retaining flexible design. Downsides for such a system include scheduling limitations for activities and the manpower required to tear down and reconfigure the space several times per day.

\subsection{Interior Design Features Rating}

Based on the literature review and discussions with $\mathrm{CAB}$ members, the researchers also rated each feature with respect to the predicted relationship between the feature and the measure of student performance (Table 5). In this specific case, features included movement and circulation patterns, spatial configuration, and interior conditions of classrooms and school facilities. The size of classroom, personal and social space, communal spaces and storage were rated as direct measurements. Additionally, space flexibility and movable furniture, and design with technologies to increase safety were believed to have an indirect impact on students, teachers and staff satisfaction of interior design. For improving the safety measures in school buildings, items such as; existence of safe rooms, identifying path for safe rooms and exit areas from classrooms were added later to the buildings assessment tool which were not discussed and rated earlier by the $\mathrm{CAB}$ members.

\section{Aesthetic Features}

\subsection{Aesthetic Literature Review}

Presently there is limited research regarding how the condition and/or aesthetics of school facilities impact student and teacher performance. One reason may be the subjective nature of this design area which deals with perceptions of art and beauty. In many cases, when measuring aesthetic conditions of spaces or elements, the results represent personal judgment of the appearance and/or beauty of elements, which is highly influenced by culture, gender, age, race or personal perceptions and likely varies from individual to individual. Accordingly, the challenge of assessing physical conditions of a space is great.

A number of researchers argue that school facility design effects student achievement, behavior, attendance, and teacher retention [60]. In his review of studies conducted between 1962 and 1978, Chan [61] determined that exceptional design may bolster

Table 5 Predicted association of CAB identified interior design features to student achievement.

\begin{tabular}{|c|c|c|c|c|}
\hline \multirow{4}{*}{ Building feature } & \multirow[b]{2}{*}{ Category } & \multicolumn{3}{|c|}{ Relationship with student outcomes } \\
\hline & & Direct & $\begin{array}{l}\text { Indirect/moderate } \\
\text { relationship }\end{array}$ & $\begin{array}{l}\text { Week/no significant } \\
\text { relationship }\end{array}$ \\
\hline & $\begin{array}{l}\text { Visibility of the interior of the classroom from the } \\
\text { main hall (ID-S-2c) }\end{array}$ & & (2) & \\
\hline & Secured Building entry (ID-S-3) & & $\mathrm{x}$ & \\
\hline \multirow{2}{*}{$\begin{array}{l}\text { Movement and } \\
\text { circulation }\end{array}$} & Circulation/interior corridors (ID-MC-1a) & & $\mathrm{x}$ & \\
\hline & Circulation/proximity to space (ID-MC-1b) & & $\mathrm{x}$ & \\
\hline \multirow{5}{*}{ Space configuration } & Interior material/long term usability (ID-SC-1a) & $\mathrm{x}$ & & \\
\hline & Interior color (ID-SC-1b) & $\mathrm{x}$ & & \\
\hline & Size of the classroom (ID-SC-3) & $\mathrm{x}$ & & \\
\hline & Personal and social spaces (ID-SC-4) & $\mathrm{x}$ & & \\
\hline & ID-SC-5 & & & $\mathrm{x}$ \\
\hline \multirow{4}{*}{ Space flexibility } & Interior flexibility/movable partition (ID-SF-1a) & & $\mathrm{x}$ & \\
\hline & Interior flexibility/movable furniture (ID-SF-1b) & & $\mathrm{x}$ & \\
\hline & Space adaptability/display surfaces (ID-SF-2a) & & $\mathrm{x}$ & \\
\hline & Space adaptability/barriers (ID-SF-2b) & & $\mathrm{x}$ & \\
\hline
\end{tabular}


achievement, because of the physiological design of the human brain which "learns faster in challenging, creative, accommodating, and healthy environments" [62].

A study conducted by Durán-Narucki seeks to explain the role that school facility condition plays in educational outcomes. The study sample included 119 elementary schools located in New York City, particularly in the Manhattan area. A "Building Condition Survey" was used to evaluate the physical condition of twenty building survey items based on their presence and relevance in daily students' activities. Architects, as external consultants, conducted the surveys by visually inspecting items and assigning them a score between 1 and 5 with 5 representing a rating of good and $1 \mathrm{a}$ rating of poor. The results indicated that school facilities with poorer conditions, were associated with lower attendance and performance in Mathematics and ESL (English as a Second Language) tests [63].

Killeen, Evans and Danko [64] studied the impact of physical learning environments on students' sense of ownership in learning. Overall the investigators found that fourth and fifth grades students in the experimental school that provided permanent displays of student work reported a significantly higher sense of ownership in the learning environment than students in a school where only temporary displays were allowed. In a study of large Texas high school facilities and their relationship to various student behaviors and performance as well as teacher turnover rates, McGowen found that although not significant, student behavior and school completion was positively associated with the availability of quality academic spaces and specialized spaces, whereas teacher turnover rates were significantly affected by teacher support space [65].

\subsection{Aesthetics Features and Results}

Overall discussions with the $\mathrm{CAB}$ resulted in an agreement that different communities have singular concepts and perceptions about aesthetic conditions. However, it was also agreed that schools with newer buildings and well-maintained facilities more effectively promoted learning, reduced dropout rates and increased student pride. The following definition was adopted for use in this project and is followed by a collaboratively developed list of features (Fig. 5) and operational definitions that comprise measures and units for this category (Appendix A).

\subsubsection{Aesthetic Features}

The physical condition of the building elements, surfaces and materials by visual inspection.

Key issues associated with this category of school features that were identified by the $\mathrm{CAB}$ include age of the school and aesthetics and student pride. A more detailed description of these issues as voiced by the $\mathrm{CAB}$ is provided below.

Age of the school and aesthetics. The members of the $\mathrm{CAB}$ noted that the age of the building was related with the physical condition of the building. In most cases, older buildings were perceived to have poorer maintenance and to be deteriorating at higher rates compared to newer schools. Also, academic spaces in poor shape were not seen as providing sufficient stimulus for learning. Consequently, the behavior of the students towards learning was negatively affected when compared to students attending newer and better physically maintained schools. However, in some schools, where high-maintenance and interior renovations were periodically performed, the age of the building was not a variable in aesthetics.

Student pride. Another issue raised by the advisory board was the relationship between school building condition and student pride. Members stated that when buildings are in poor condition students feel they are not supported and recognized. Accordingly, there is no sense of belonging and the cycle of physical deterioration is accelerated. In other words, if the facilities are not well maintained, then, students do not exert any effort to preserve or avoid damaging the school facility. As a result, the learning environment 


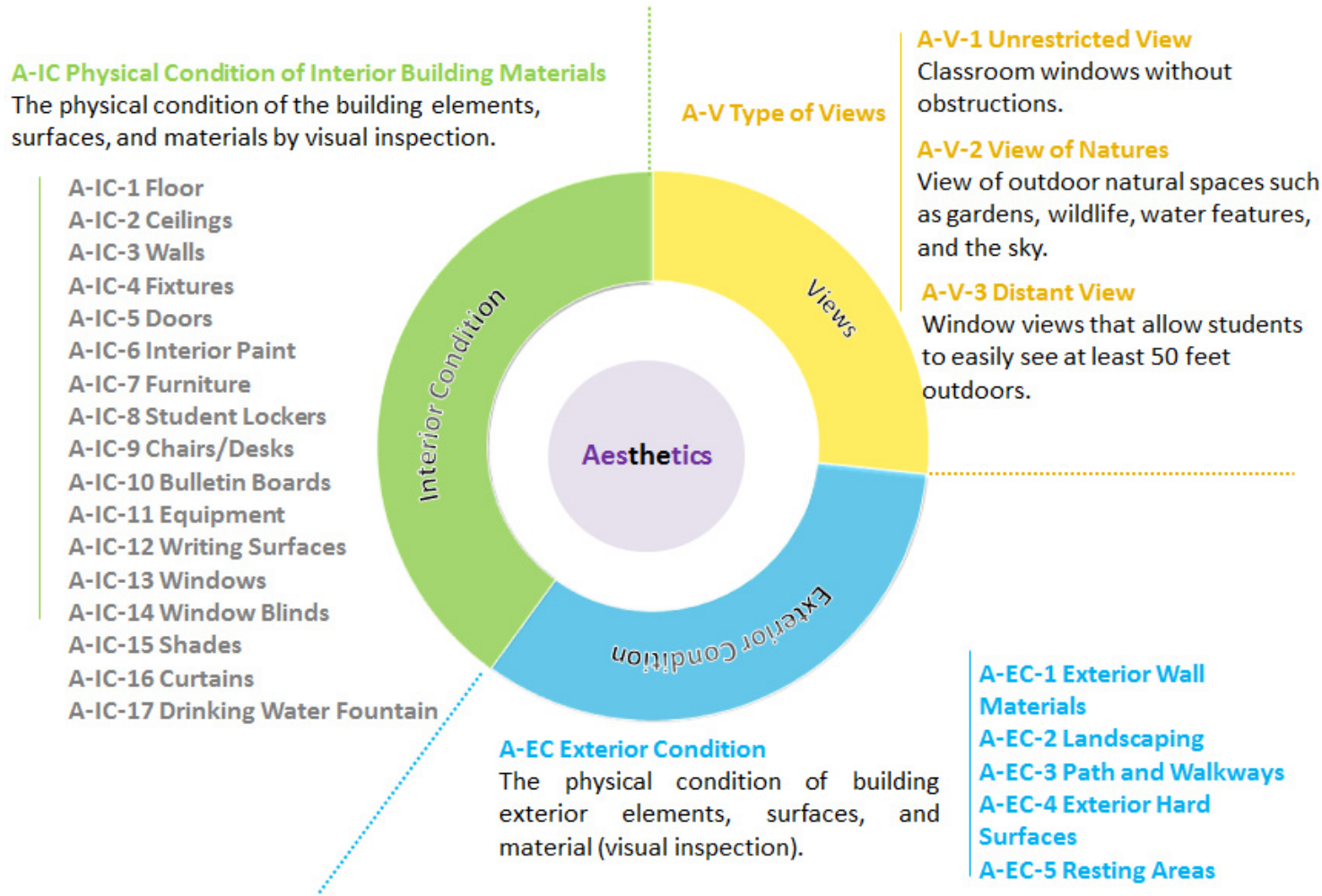

Fig. 5 Aesthetic features.

Table 6 Predicted association of CAB identified aesthetic features to student achievement.

\begin{tabular}{|c|c|c|c|c|}
\hline \multirow[b]{2}{*}{ Building feature } & \multirow[b]{2}{*}{ Category } & \multicolumn{3}{|c|}{ Relationship with student outcomes } \\
\hline & & Direct & $\begin{array}{l}\text { Indirect/moderate } \\
\text { relationship }\end{array}$ & $\begin{array}{l}\text { Week/no significant } \\
\text { relationship }\end{array}$ \\
\hline \multirow{3}{*}{ Views } & Unrestricted view $(\mathrm{A}-\mathrm{V}-1)$ & $\mathrm{x}$ & & \\
\hline & View of natures (A-V-2) & $\mathrm{x}$ & & \\
\hline & Distant niew (A-V-3) & $\mathrm{x}$ & & \\
\hline Interior condition & $\begin{array}{l}\text { Physical condition of interior building materials } \\
\text { (A-IC) }\end{array}$ & $\mathrm{x}$ & & \\
\hline \multirow{5}{*}{ Exterior condition } & Exterior wall materials (A-EC-1) & & $\mathrm{x}$ & \\
\hline & Landscaping (A-EC-2) & & $\mathrm{x}$ & \\
\hline & Path and walkways (A-EC-3) & & $\mathrm{x}$ & \\
\hline & Exterior hard surfaces (A-EC-4) & & $\mathrm{x}$ & \\
\hline & Resting areas (A-EC-5) & & $\mathrm{x}$ & \\
\hline
\end{tabular}

is affected.

\subsection{Aesthetics Features Rating}

Considering the literature review, the input from the community advisory board, and key informants, aesthetic features were also rated based on the hypothesized direct effect on student/teacher performance, an indirect affect through other factors, or little to no significant relationship to the final outcome measure at this level of study. Table 5 displays the assumed relationship between specific aesthetic related building elements to student performance ranging from direct to weak or no significant relationship.

Interior condition is the first category rated as directly affecting student performance. If building features that comprise the space such as wall, doors, ceilings, windows and floors are not in good condition, they 
will serve as distractors for students. Additionally, learning activities performed in the classrooms are affected if the functional interior elements such as desks, writing surfaces and equipment, among others, are in poor condition. On the other hand, exterior features were determined to have an indirect relationship on learning environments. Finally, outside views were identified as features that directly impact student performance. In this case, it is important to provide an environment with unobstructed views or views of nature as they should relieve stress for students and teachers and have been found to be positively associated with standardized tests scores, graduation rates, and plans to attend four year-college [66, 67].

\section{Conclusion}

Providing an optimal learning environment including both safety and productivity for students and teacher has been an issue for many school decision makers when they decide to do a new construction or renovation on school buildings. Considering these issues along with the lack of a comprehensive list of building features affecting student outcomes were the first steps in the OKHS research project. Thus, the research team attempted to identify a list of school building components that are believed to affect student performance and can be tested for statistical associations with student performance.

The research team created a comprehensive list of building features, including their related components, items, and standards through different steps. First, the research team did a deep literature review to figure out the most important and influential school building features and factors and how much these building components are affecting students' outcomes. Second, they did interviews with teachers, parents, nurses, and school leaders along with consulting with the $\mathrm{CAB}$ and school design firms to complement the literature review. For narrowing down the potential features list, the researchers and school experts, based on professional experience, rated how directly related each building feature was to student performance. Finally, the research team created a building assessment tool, that is provided in Appendix B, to measure these building features. The purpose of providing this building instrument was to help school decision makers, researchers, and other stakeholders have a comprehensive source of necessary considerations and requirements at the time of designing, constructing, and renovating school buildings or doing related research for school buildings/facility design and other educational environments.

\section{Future Research}

The provided building assessment tool, serves as a starting point to determine which features have the greatest effect on student performance. In later phases of the OKHS project, hypothesized relationships between identified building features and student performance will be tested statistically and the correlation between each category with student performance will be analyzed.

So far, this research has limitations that can be improved in later related research. For instance, future research may consider a bigger sample of school buildings that improves accuracy of results. Also, this research considered similar school building materials and similar HVAC system for school buildings. This could be expanded to obtain greater ranges of results. Future research could consider that the student outcomes are obtained from various sources, rather than a single source of testing. In addition, in our research, the outcome variables are based on student performance at the school level and accuracy could be improved if classroom level scores are available.

\section{Acknowledgments}

The OU Healthy Schools Project is funded by the U.S. EPA (Environmental Protection Agency), STAR 
(Science to Achieve Results) Initiative, Grant \#83563401-0. The project is a collaboration of many people including but not limited to Jacob Bartels, Research Assistant, OUHSC (University of Oklahoma Health Sciences Center), College of Public Health, Lisa Holliday, Ph.D., OU College of Architecture, Amanda E. Janitz, Ph.D., OUHSC College of Public Health David L. Johnson, Ph.D., OUHSC College of Public Health, Marguerite Keesee, Ph.D., OU Center for Spatial Analysis, Robert A. Lynch, Ph.D., OUHSC College of Public Health, Sheryl Magzamen, Ph.D., CSU (Colorado State University) College of Veterinary Medicine \& Biomedical Services, Camilo Pena, OU College of Architecture, Hans Peter Wachter, M.arch, Dipl.Ing, LEED AP, Green AP, CAPS, NCIDQ, OU College of Architecture and the OKHS CAB. This project would not have been possible without the participation of the Oklahoma City Public School District, the Edmond Public School District and the Frankfurt-Short-Bruza Architectural-Engineering-Planning firm.

\section{References}

[1] Marshall, T. P. 2002. "Tornado Damage Survey at Moore, Oklahoma." Weather and Forecasting 17: 582-99.

[2] Earthman, G. I., and Lemasters, L. 1996. "Review of Research on the Relationship between School Buildings, Student Achievement, and Student Behavior." International Council of Educational Facility Planners, Educational Resources Information Center (ERIC), Tarpon Springs, FL., 18.

[3] Earthman, G. I. 2004. "Prioritization of 31 Criteria for School Building Adequacy." American Civil Liberties Union Foundation of Maryland. Accessed 2016. http://www.schoolfunding.info/policy/facilities/ACLUfac ilities report1-04.pdf.

[4] DiLaura, D., Houser, K., Mistrick, R., and Steffy, G. 2011. The Lighting Handbook. New York, NY: Illumination Engineering Society of North America.

[5] Society of Light and Lighting. 2009. SLL Lighting Handbook. London, UK: CIBSE.

[6] Heschong L. 1999. "Daylighting in Schools: An Investigation into the Relationship between Daylighting and Human Performance (HMG Project \#9803)." Heschong Mahone Group to Pacific Gas and Electric Company on behalf of the California Board for Energy
Efficiency Third Party Program. Accessed May 16, 2016. http:/files.eric.ed.gov/fulltext/ED444337.pdf.

[7] Nicklas, M. H., and Bailey, G. B. 1996. "Student Performance in Daylit Schools." Innovative Design. Raleigh, North Carolina.

[8] Plympton P., Conway, S., and Epstein K. 2000. "Day Lightening in Schools: Improving Student Performance and Health at a Price School Can Afford." NREL/CP-550-28049, National Renewable Energy Laboratory, USA.

[9] Grangaard E. M. 1995. "Color and Light Effects on Learning." Paper Presented at International Study Conference and Exhibition, Washington, DC.

[10] Guy, R. 2009. "Acoustics in the Built Environment." In Sustainable Built Environment, edited by Haghighat, F. and Kim, J.-J. Oxford, United Kingdom: EOLSS/UNESCO, 405.

[11] Sheild, B. M., and Dockrell, J. E. 2003. "The Effect of Noise on Children at School: A Review." Building Acoustics 10: 97-116.

[12] ANSI (American National Standard Institute). 2010. ANSI/ASA S12.60-2010/Part 1 American National Standard/ Acoustical Performance, Criteria, Design Requirements, and Guidelines for Schools. New York: Acoustical Society of America.

[13] Ronsse, L. M., and Wang, L. M. 2010. “AB-10-C037: Effects of Noise from Building Mechanical Systems on Elementary School Student Achievement." DigitalCommons@University of Nebraska.

[14] Malik, H., and Farid, H. 2010. "Audio Forensics from Acoustic Reverberation.” 2010 IEEE International Conference on Acoustics Speech and Signal Processing (ICASSP), Dallas, TX, USA.

[15] Kristiansen, J., Persson, R. P., Hitomi, S., and Nielsen, P. M. 2013. "Effects of Classroom Acoustics and Self-reported Noise Exposure on Teachers' Well-Being." Environment and Behavior 45 (2): 283-300.

[16] Sabine, W. C. 1964. Collected Paper on Acoustic. New York: Dover Publications.

[17] Crandell, C., and Smaldino, J. 2000. "Room Acoustic for Listener with Normal-hearing and Hearing Impairment." In Audiology: Treatment, edited by Valente, M., Hosford-Dunn, H., and Roeser, R. New York: Thieme Medical Publishers, 601-23.

[18] Haines, M. M., Stansfeld, S. A., Job, R. F. S., Berglund, B., and Head, J. 2001. "A Follow-up Study of Effects of Chronic Aircraft Noise Exposure on Child Stress Responses and Cognition." International Journal of Epidemiology 30: 839-45.

[19] Moslemi Haghighi, M., Chiao, L. E., and Bin Mohd Jusan, M. 2012. "Effect of Acoustic on Students' Performance in Secondary Classroom Environment: A 
Review." International Journal of Modern Engineering Research (IJMER) 2 (4): 2557-60.

[20] Knecht, K. A., Nelson, P. B., Whitelaw, G. M., and Feth, L. L. 2002. "Background Noise Level and Reverberation Times in Unoccupied Classrooms: Predictions and Measurements." American Journal of Audiology 11: 2.

[21] Maxwell, L., and Evans, G. W. 1997. "Chronic Noise Exposure and Reading Deficits: The Mediating Effects of Language Acquisition." Environment and Behavior 29 (6): 638-56.

[22] Weinstein, C. S. 1979. "The Physical Environment of the School: A Review of the Research." Review of Educational Research 49 (4): 577-610.

[23] Brown, S. K. 1997. "Indoor Air Quality, Australia: State of the Environment Technical Paper Series (Atmosphere)." Department of the Environment, Sport and Territoties, Canberra.

[24] Mendell, M. J., and Heath, G. 2005. "Do Indoor Pollutants and Thermal Conditions in Schools Influence Student Performance? A Critical Review of the Literature." Indoor Air Journal 15: 27-32.

[25] Tom, S. 2008. "Managing Energy and Comfort." ASHRAE Journal 50 (6): 18-26.

[26] New York State Department of Health. 2010. "Classroom Design Standards." Bureau of Emergency Medical Services, New York State Department of Health, New York. Accessed Sept. 23, 2016. www.health.ny.gove/professionals./ems/education/course _sponsors/docs/classroom_design_standards.pdf.

[27] Wargochki, P., Wyon, D. P., Matysiak, B., and Irgens, S. 2005. "The Effects of Classroom Air Temperature and Outdoor Air Supply Rate on the Performance of School Work by Children." Proceeding of indoor Air 1 (1): 368-72.

[28] Wargochki, P., and Wyon, D. P. 2007. "The Effect of Moderately Raised Classroom Temperature and Classroom Ventialtion Rate on the Performance of Schoolwork by Children (RP-1257)." HVAC \& $R$ Research 13 (2): 193-220.

[29] Wafi, S. R. S., and Ismail, M. R. 2008. "The Relation between Thermal Performance, Thermal Comfort and Occupants." 2nd International Conference on Built Environment in Developing Countries (ICBEDC).

[30] Sailor, D. J. 1995. "Simulated Urban Climate Response to Modifications in Surface Albedo and Vegetative Cover." Journal of Applied Meteorology 34 (7): 1694-704.

[31] Hernández-Pérez, I., Álvarez, G., Xamán, J., Zavala-Guillén, I., Arce, J., and Simá, E. 2014. “Thermal Performance of Reflective Materials Applied to Exterior Building Components-A Review." Energy and Buildings 80: 81-105.
[32] Harner, D. P. 1974. "Effects of Thermal Environment on Learning Skills.” CEFP Journal 12 (2): 4-6.

[33] Brager, G. S., Paliaga G., and de Dear, R. 2004. "Operable Windows, Personal Control, and Occupant Comfort." ASHRAE Transaction 110 (2): 17-35.

[34] Van Hoof, J. 2008. "Forty Years of Fanger's Model of Thermal Comfort: Comfort for All?" Indoor Air 18 (3): 182-201.

[35] Karjalainen, S. 2012. "Thermal Comfort and Gender: A Literature Review.” Indoor Air 22 (2): 96-109.

[36] Parsons, K. 2014. "Thermal Comfort for Special Populations."In Human Thermal Environments. CRC Press, 307-22.

[37] Earthman, G. I., and Lemasters, L. K. 1997. "Can Research Findings Help School Systems Obtain the Most Bang for the Construction Bucks?" Council of Educational Facility Planners Annual Meeting, Education Resources Information Center (ERIC), 43.

[38] Lumpkin, R. B., Goodwin Jr., R. T., Hope, W. C., and Lutfi, G. 2014. "Code Compliant School Buildings Boost Student Achievement.” SAGE Open 4 (4): 1-8.

[39] Filardo, M. 2016. State of Our Schools: America's K-12 Facilities 2016. Washington, DC: 21st Century School Fund.

[40] Weinstein, C. S. 1979. "The Physical Environment of the School: A Review of the Research." Review of Educational Research 49 (4): 577-610.

[41] Schneider, M. 2002. "Do School Facilities Affect Academic Outcomes?" National Clearinghouse for Educational Facilities, U.S. Department of Education. $\begin{array}{llll}\text { Accessed } & \text { Sept. } & 12,\end{array}$ http://www.edfacilities.org/pubs.

[42] Guo, Y., Piasta, S. B., Justice, L. M., and Kaderavek, J. N. 2010. "Relations among Preschool Teachers' Self-efficacy, Classroom Quality, and Children's Language and Literacy Gains." Teaching and Teacher Education 26 (4): 1094-103.

[43] Barrett, P., Zhang, Y., Moffat, J., and Kobbacy, K. 2013. "A Holistic, Multi-level Analysis Identifying the Impact of Classroom Design on Pupils' Learning." Building and Environment 59: 678-89.

[44] Biddle, B. J., and Berliner, D. C. 2014. "Small Class Size and Its Effects." In Schools and Society: A Sociological Approach to Education, edited by Ballantine, J. H., and Spade, J. Z. Los Angeles, CA: Sage, 76-85.

[45] Barrett, P., Davies, F., Zhang, Y., and Barrett, L. 2015. "The Impact of Classroom Design on Pupils' Learning: Final Results of a Holistic, Multi-level Analysis." Building and Environment 89: 118-33.

[46] Smith, T. M., Thompson Rogers, G., Alsalam, N., Perle, M., Pratt Mahoney, R., and Martin, V. 1994. "The Condition of Education 1994." National Center for 
Education Statistics, U.S. Department of Education, Washington, DC.

[47] Tanner, C. K. (2008a). "Explaining Relationships among Student Outcomes and the School's Physical Environment." Journal of Advanced Academics 19: 444-63.

[48] Tanner, C. K. (2008b). "Effects of School Design on Student Outcomes." Journal of Education Administration 47 (3): 381-99.

[49] Smith, P. 1907. "Defects in the Schools and the Responsibility for Them- (IV)." The Journal of Education 65 (21 (1631)): 572-3.

[50] Dobbs, E. V. 1935. "Overcrowding the Primary School." Childhood Education 11 (4): 159.

[51] Boots, B. N., and Ahonen, J. 1978. "Urban Crowding and Its Consequences." Economic Geography 54 (2): 184-6.

[52] Lewis, L., Snow, K., Farris, E., Smerdon, B., Cronen, S., Kaplan, J., and Greene, B. 2000. "Condition of America's Public School Facilities: 1999 (NCES 2000-032)." National Center for Education Statistics, U.S. Department of Education, Washington, DC.

[53] Mosteller, F. 1995. "The Tennessee Study of School Grades." Critical Issues for Children and Youths 5 (2): 113-27.

[54] Finn, J. D., Pannozzo, G. M., and Achilles, C. M. 2003. "The 'Why's' of Class Size: Student Behavior in Small Classes." Review of Educational Research 73 (3): 321-68.

[55] Finn, J. D., and Achilles, C. M. 1999. "Tennessee's Class Size Study: Findings, Implications, Misconceptions." Educational Evaluation and Policy Analysis 21 (2): 97-109.

[56] Biddle, B. J., and Berliner, D. C. 2015. "Small Class Size and Its Effects." In Schools and Society: A Sociological Approach to Education, edited by Ballantine, J. H., andSpade, J. Z. Los Angeles, CA: Sage, 76-85.

[57] Aiello, J. R., and Aiello, T. D. C. 1974. "The Development of Personal Space: Proxemic Behavior of Children 6 through 16." Human Ecology 2 (3): 177-89.

[58] McGuffey, C. W. 1982. "Facilities." In Improving
Educational Standards and Productivity: The Research Basis for Policy, edited by Walberg, H. J. Berkeley, CA: McCutchan, 237-88.

[59] Aiello, J. R., Thompson, D. E., and Baum, A. 1985. "Children, Crowding, and Control: Effects of Environmental Stress on Social Behavior." In Habitats for Children: The Impacts of Density, edited by Wohlwill, J. F., and van Vliet, W. Hillsdale, NJ: Lawrence Erlbaum Associates, 97-124.

[60] O'Neill, D. 2000. "The Impact of School Facilities on Student Achievement, Behavior, Attendance, and Teacher Turnover Rate at Selected Texas Middle School in Region XIII ESC." Unpublished doctoral dissertation. College Station, TX, Texas A\&M University.

[61] Chan, T. C. 1996. "Environmental impact on student learning." A paper of School of Education, Valdosta State coll., GA.

[62] Chan, T. C., and Petrie, G. 1998. "The Brain Learns Better in Well Designed School Environment." Association of Supervision and Curriculum Development: Classroom Leadership Online 2 (3): 1.

[63] Durán-Narucki, V. 2008. "School Building Condition, School Attendance, and Academic Achievement in New York City Public Schools: A Mediation Model.” Journal of Environmental Psychology 28 (3): 278-86.

[64] Killeen, J. P., Evans, G. W., and Danko, S. 2003. "The Role of Permanent Student Artwork in Students' Sense of Ownership in an Elementary School." Environment and Behavior 35 (2): 250-63.

[65] McGowen, R. S. 2007. "The Impact of School Facilities on Student Achievement, Attendance, Behavior, Completion Rate and Teacher Turnover Rate in Selected Texas High Schools." Texas A\&M University.

[66] Tanner, C. K. 2009. "Effects of School Design on Student Outcomes." Journal of Education Administration 47 (3): 381-99.

[67] Matsuoka, R. H. 2010. "Student Performance and High School Landscapes: Examining the Links." Landscape and Urban Planning 97 (4): 273-82. 


\section{Appendix A: Building features definitions and descriptions.}

Below is a list of building features that were collaboratively developed by OKHS research staff and CAB members. Features are categorized by main feature categories. Operational definitions and measurement metrics are included as well as variable codes used. Individual features may be included in more than one feature category as individual building features can have more than one function.

Lighting (L)

Lighting in this research refers to purposefully use of light, both daylight and artificial light, in order to achieve academic and practical effect on students.

Type and Source of Daylight (L-TS)

Orientation of the Windows (L-TS-1/TC-LCS-1) Direction windows face in the room. Data are collected though visual inspection with each possible combination of direction listed on the assessment form. For all windows in the room, assessors place a check mark next to each direction that a window faces in the room. A checked direction is scored as one with not checked directions receiving a code of 0 .

Lighting Sources (L-TS-2)

Daylight (L-TS-2a)

Existence of daylight/daylight in a class room. Windows and skylights were considered as kinds of openings that penetrated daylight into the classroom.

\section{Lighting Fixtures (L-TS-2b)}

Existence of any lighting source other than daylight like; LED, fluorescent, and incandescent in classrooms. This feature was considered through reviewing plans and drawings of schools' buildings.

\section{Task Lighting (L-TS-3)}

Identifying the amount of daylight combined with artificial lights existed in classrooms. Lighting in study rooms was measured through using the light-meter. Light/illumination measurements reported based on the foot-candle (fc) unit. Researchers took five different samples in different spots marked as four different corners of a classroom which one of them included the teacher desk and the fifth spot was the center of the class room. All the measurements have been taken during the day when students were performing in classrooms. In addition, the geographical location for all inspected buildings was the same. This would make the process of comparing data and analyses possible in the later phase of the research. No specifications relating to the condition of the sky and weather is taken into account.

The purpose of taking five different measurements in a classroom was figuring out how the amount of lighting distributed within the classroom. Considering the direct relation of daylighting on student awareness and performance, all of the below lighting subcategories which are going to influence the amount and proportion of penetrating external and daylight may also affect student performance.

\section{Glare (L-TS-4)}

Existence of strong and uncontrolled amount of light in a classroom. Glare can be created by the existence of too much amount of daylight and artificial light in a room. Existence of glare in classrooms may distract students from their concentration and relatively affects student performance. Data related to glare were recorded while visual observation and according to viewer's personal judgment.

\section{Windows (L-W)}

\section{Amount of Walls with Windows (L-W-1)}

Number of walls in a classroom including windows. In the later statistical analysis, numeric was a representation of the number of walls with window. For instance, 0 was for no wall with window and 1 was for one wall with windows. 


\section{Dimension of Windows (L-W-2)}

Ratio of total window area to total floor area. Areas of windows were measured in Square-Feet and if more than one window was provided for the room, sum of the windows' Square-Feet were measured and finally the total windows' area were divided to the room Square-Feet. Bigger window to floor ratio is supposed to provide more daylight in a room and influence room temperatures.

Window Blocked (L-W-3)

Identifying elements which block daylight in a room not including louvers, baffles, and shades.

Skylight (L-W-4/TC-LCS-3)

Existence of skylight in the roof or ceiling that penetrate daylight which affect the quality and quantity of light and the amount of thermal comfort in a room.

Lighting Control System (L-CS)

Louver, Baffle, and Shades (L-CS-1)

All window adjustable elements designed to control penetration of direct sunlight. Having lighting control devices on windows would improve the quality of the amount of existing light in a room. Researchers assessed this feature through visual inspection.

Louver, Baffle, and Shades (L-CS-2)

Identifying operable shading devices designed to modify sunlight/day lit.

\section{Lighting Fixture Blocked (L-CS-3)}

Occupants install blocking elements and objects which block lighting fixtures, not including intentional shading devices like a lamp- shades. The existence of blocking elements was considered as a negative point for studied rooms.

\section{Topography (L-CS-4/TC-DC-3)}

Exterior site feature which may cover, protect or block penetration of sunlight/daylit and also affect the amount of thermal comfort in a room. Researchers considered the room as: (A) Completely, (B) Partially, and (C) Not below the ground. Topography was identified through visual inspection and reviewing building drawings. Moreover, the existence of topography structure helps rooms reduce thermal interaction with outside and acts as insulation for the room. This item helps the building stay cooler during hot seasons and warmer during cold seasons.

\section{Blocking Elements (L-CS-5)}

Elements which block direct sunlight/daylight in the room not including shading devices such as louver, baffle, and shades.

\section{Spatial Configuration (L-SC)}

\section{Form/Shape of the Room (L-SC-1/A-SC-1/TC-DC-2)}

Irregular configurations considered as shapes and forms which all their sides and angles are not equal. This inequality can take place in walls, floor, and ceiling surfaces. The geometry and configuration of a room may affect the quality of lighting, acoustic, and thermal comfort in a room. Form/shape of the room was reviewed through reading elevations and floor plans of school buildings' drawing. The amount of penetration of daylight into a room that identifies both the quality and quantity of light can be affected by the room configuration, its width and depth. Existence of irregular configuration also affects the amount of acoustics, the movement of sound within the room, and reverberated sounds produced in rooms. In addition, for rooms with regular shape and equal sides and angles, a homogenous temperature flow is existed thus; different corners and spots of the room may have the same temperature.

\section{Acoustic (A)}

Acoustics refers to the generation, transmission, and reception of sound in both open and enclosed spaces and its effect. The acoustic environment should support the transmission of clear speech and diminish the effect of background and other distracting noises.

\section{Source of Noise (A-SN)}

Decibel Meter (A-SN-1) 
The research team took three to five different samples in different spots including four corners and center of the room. Researchers used the Decibel- Meter for measuring the amount of produced sounds in a studying room and the unit that was used for recording measures was decibel. All the measurements were taken during the day when students performed their normal activities in rooms. Different activities may take place in classrooms such as: reading, writing, watching a movie, and playing which are producing different acoustic levels. Studied classrooms were categorized according to the activities done in them and the final result of the research visual inspection shows that majority of studied rooms were homerooms which normal teaching, reading, and writing activities took place in them.

Source of Noises (A-SN-2)

Source of noise identified as systems, spaces, and backgrounds that produce noise in rooms. The source of noise can be identified as:

\section{A-SN-2a HVAC System}

A-SN-2b Desk, Computers, others

A-SN-2c Noise Adjacent to the Classroom

A-SN-2c-1 Parking and Street

A-SN-2c-2 Service Rooms

A-SN-2c-3 Playground

A-SN-2c-4 Gym, Cafeteria, and Recreational Spaces

A-SN-2d Bell System

A-SN-2e Lighting Fixtures

Spatial Configuration (A-SC)

Glass and Window System (A-SC-2)

The system of glass and window including the type of used materials and dimensions.

\section{Dimension (A-SC-2a)}

Calculating the ratio of existed window area to the area of walls consist of windows. All areas calculated in square feet.

\section{Glass and Window System (A-SC-2b/TC-LCS-4)}

The type/ material of the glass as part of the windows' system in the room. The type of the glazing system was found through reviewing school building drawings. An instance of the glass/window system is a glazed window with low e-glass or double glazed windows with argon inch between 1/8 and 1/4 inches' glass thickness. Double paned windows decreases thermal interaction between inside and outside of a room and improve temperature stability. It also helps decrease the amount of background noise in a room.

\section{Occupancy Type (A-OT)}

\section{Room activity (A-OT-1)}

Defining type of the activity that makes noise in the room/space. Students' performance in rooms directly related to the produced acoustic level. Different activities such as reading, writing, playing, watching a movie, listening, taking a test create different decibel levels. For this purpose, inspected rooms are categorized based on activities performing in them.

\section{Population Density (A-OT-2)}

The average number of people using the space/amount of crowd in a space that affects the amount of produced noise is defined under this item. For this purpose, the total area of the studied room (in square feet) divided by the number of students using the room and if students were not in the classroom, the room area divided by the number of chairs existing in the room.

Thermal Comfort (TC)

Design Components (TC-DC)

Room Temperature (TC-DC-1) 
The temperature of top surfaces of five desks located in four different corners and the center of the room was measured. The selected desks were using desks by students and teachers. Researchers used a Thermostat Meter for measuring the temperature and they reported the recorded data based on the Fahrenheit (F) unit. They took the measurements during the day when students were doing their normal activities in classrooms.

Operable Window (TC-DC-5 a)

Occupants can open windows. Operable windows affect the room temperature if occupants are willing to use them. The existence of an operable window in a room is considered as a positive point. In addition, operable windows may provide cross ventilation affecting the room air circulation.

Other Heating and Cooling Sources (TC-HS)

HVAC System (TC-HS-1)

Identifying types of the HVAC systems used in the building like centralized, independent, or roof top units.

Thermostat Control (TC-HS-1a)

The thermostat can be adjusted by occupants. Researcher, through visual inspection and also asking from teachers in each studied room, identified that occupants can control the room temperature using thermostat control or not.

\section{Lighting Fixtures (TC-HS-2)}

Identifying type of the light bulb the releases heat. Considering different types of lights, other than daylight, used in classrooms including incandescent, fluorescent, and LEED, may produce heat and affect the room temperature.

Appliances and Equipment (TC-HS-3)

Specifying elements that release heat affecting room temperature such as; lab equipment, computers, and portable heaters.

\section{Lighting Control System (TC-LCS)}

Shading Devices (TC-LCS-3)

Identifying any exterior or interior physical elements including louvers, shades, baffles etc. that control direct sunlight affecting the amount of sunlight penetrating into the room and affecting the room temperature.

Blocking Elements (TC-LCS-4)

The existence of elements that block direct sunlight, not including shading devices like: louvers, baffles, and shades. Any interior o exterior blocking elements such as furniture, posters, lockers, trees or any other vegetation that block daylight and affect room temperature.

\section{Interior Design (ID)}

Space Configuration (ID-SC)

Interior Material (ID-SC-1)

Long- Term Usability (ID-SC-1a)

Identifying the manufacturer's life cycle, warranty, and usability of carpet, upholstery, and laminates. Sustainability of interior material is related to their long term usability. Sustainable materials with long life cycle are hypothesized to promote students' learning and health. Researchers identified this feature through reviewing specification books of school buildings.

\section{Interior Color (ID-SC-2)}

Identifying the color of an interior wall, floor, and furniture in a room. Considering the effect of interior space and color on students' productivity, researchers identified the effect of used color on both the light and the productivity. The research team identified white color as the most, neutral colors including beige, light brown, gray etc. as the second most and other colors including red, blue, green etc. as the less effective colors on classrooms' light. Moreover, the neutral colors as the most, the white color as the second most and other colors as the less effective colors on students' productivity. 


\section{Size of the Classroom (ID-SC-3)}

Providing an enough space for each student will directly affect their productivity and performance. The rooms' sizes were measured in square feet unit. The size of rooms has a direct relation with population density and for finding the population density of each studying room researchers calculated the ratio between a room area to a number of students using the room and if students were not available, to a number of existing chairs in a room.

Personal and Social Spaces (ID-SC-4)

The personal space is a space dedicated for each student to sit and perform their activities without any interruption. For calculating the personal/social spaces, the researchers measured the distance of the center of a desk to the front, back, and lateral surrounding desks. They used the laser meter for their measurements, and they recorded their measures in foot unit.

Storage (ID-SC-5)

Storage defined as a secured individual space for student belonging and secured spaces for media and learning equipment, tools, supplies, and teacher belongings. Researchers identified this item through reviewing plans and drawing of the building.

\section{Space Flexibility (ID-SF) \\ Interior Flexibility (ID-SF-1) \\ Movable Partition (ID-SF-1a)}

Ability to vary the configuration of the room through movable walls and partitions. Flexible spaces will benefit students by providing different arrangements according to students' activities in a room. It should be taken into account that changing a room configuration through using partitions may affect the amount of light, acoustic, and temperature in a room. Incorrect arrangements may block the natural/artificial light or homogeneous acoustic and temperature in a room.

\section{Movable furniture (ID-SF-1b)}

Existence of interior furniture which can rotate/move around the space. Activities such as group working may require a communal area. Besides, it is necessary for students to have their own individual space while they are performing studying activities such as reading, writing, etc. Through flexible furniture, students and teachers are able to change the arrangement of desks and chairs according to the activity that they are going to perform.

Space Adaptability (ID-SF-2)

Display Surfaces (ID-SF-2a)

Existence of designated area for displaying students' works, drawings, and achievements.

Barriers (ID-SF-2b)

Existence of any physical or visual barriers, structures, or objects like; interior columns which interfere with the line of sight for instruction. Existence of barriers identified through classroom visual inspection.

\section{Movement and Circulation (ID-MC)}

Circulation (ID-MC-1)

Interior Corridors (ID-MC-1a)

Identifying the amount of crowd in corridors which are connecting classrooms during class change time. This item is perceived by researcher through visual inspection.

Proximity to spaces (ID-MC-1b)

Measuring distances between classrooms to bathrooms and water fountains and how close are classrooms to these spaces. Researcher identifies this item through reviewing drawings and plans of the school buildings. They used Laser Meter for their measurements and they recorded their measure in foot unit.

Safety (ID-S)

Existence of safe rooms (ID-S-1) 
Providing shelter are/safe room in school buildings for students and teachers in case of tornado or hurricane. Researchers identified this item through school building visual inspection and reviewing drawings of the buildings.

Visibility (ID-S-2)

Identifying Path for Safe Rooms (ID-S-2a)

Clear routes for safe areas are visible upon existing classroom. Researchers identified this item through school building visual inspection.

\section{Identifying Path for Exit Areas (ID-S-2b)}

Clear routes for exit areas are visible upon existing classroom. Researchers identified this item through school building visual inspection.

Visibility of the Interior of the Classroom from the Main Hall (ID-S-2c)

The interior of a classroom is exposed to main hallways. The main hallway defined as a corridor which is within two turns of the main entrance of the building. Providing this feature is considered as a point for classrooms in case of observing classrooms and bad option in case of shooters attacking.

Secured Building entry (ID-S-3)

Identifying secured, operable, and used entry process into the building. Availability of a secured building entry means that the building provides either a medium amount of security, which means that visitors could get into the building without any announcement but they should be checked at the front desk or highly secured entry, which means visitors should announce the office before getting checked in. In some schools, visitors should first be checked by a laser scanner before getting to the office.

Aesthetics (A)

Type of Views (A-V)

Unrestricted View (A-V-1)

Windows of study rooms obstructed to outside view. Researchers tried to figure out that students can see outside of classrooms without any obstruction. Views of outside can be totally or partially obstructed. Items related to views collected by the research team through school building visual inspection.

View of Nature (A-V-2)

The room provided views of outdoor and natural spaces such as; gardens, wildlife, fountains, mountains, sky, etc.

\section{Distance View (A-V-3)}

Determining the distance between windows and the closest outside obstruction. If the view of outside provided for classrooms, students are able to see at least 50 feet distance of outside. The research team collected data for this item through visual inspection and by using laser meter. The collected measurements were recorded in foot unit. The obstruction can be any obstacle that blocks the outside view including; buildings, air conditioner systems, trash cans, etc.

Interior Condition (A-IC)

The physical condition of the building elements, surfaces, and materials. Researchers collected the building condition data through visual inspection. Building materials that they considered for this item were: floor, ceiling, walls, fixtures, doors, interior paints, furniture, student lockers, chairs/desks, bulletin board, equipment, writing surfaces, windows, window blinds, shades, curtains, and drinking water fountain.

\section{Exterior Condition (A-EC)}

The physical condition of building exterior elements, surfaces, and materials including; exterior wall materials, landscaping, path and walkways, exterior hard surfaces (such as concrete, paves, blacktop, and wood deck), and resting areas (such as benches). 
Appendix B: Building features assessment tool.

\section{Date:}

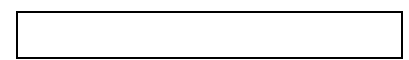

Starting Time

\section{GENERAL}

1) Name of the assessor
2) Specify type of school.
Elementary school
Middle school
Mid-high school
High school

3) Type Name of school

4) Room activity: Use of the space based on activities
Math
Science
English
Gym
Computer lab
Homeroom/multiple subjects (elementary schools/special educational classroom)
Safe room
$\bigcirc \quad$ Other

5) Classroom number

6) Average number of students in classroom being observed per hour?

\section{OR if there are no students, count chairs in the classroom}

\section{LIGHTING}

L-TS-1/TC-LCS-1) Orientation of the windows: Identify the windows face direction in a room. $\checkmark \cdot$ Compass: Specify the location of the windows (N/W/E/S-Combinations). Select all that apply.
North
South
West
East
North-west
North-east
South-west
South-east 
L-TS-2a) Day Light, day-lit: Can sunlight penetrate into the room?

$\sqrt{ } \cdot$ Visual inspection: Mark the circle to the left of the corresponding.
Y Yes
No

L-TS-3) Lighting: With an Illuminance meter, measure light in 5 different spots (teacher +4 students desks) in the room.

$\sqrt{ } \cdot$ Digital light meter: The digital light meter must be in foot-candles (fc), and all lighting fixtures must be ON. Write each measure in the corresponding box

Measure No. 1 (Corner Desk A)
Measure No. 2 (Corner Desk B)
Measure No. 3 (Corner Desk C)
Measure No. 4 (Corner Desk D)
Measure No. 5 (Teacher Desk)

L-TS-4) Glare: Are any spots or areas of concentrated harsh uncomfortably brilliant light for the occupants?

$\sqrt{ } \cdot$ Visual inspection: Mark the circle to the left of the corresponding.
Y Yes
No

L-W-1) Amount of walls with windows: Count the number of walls with windows in the room.

$\sqrt{ }$ Visual inspection: Mark the circle to the left of the corresponding.
No walls with window windows
One wall with window windows
Two or more walls with windows

L-W-5/TC-LCS-1) Skylights: Are any openings in the roof which admit natural light into the room?

$\sqrt{ } \cdot$ Visual inspection: Mark the circle to the left of the corresponding.

$\mathrm{O}^{\bigcirc}$ Yes

L-CS-1) Louvers, baffles or shades: Adjustable window elements (shading devices) designed to control penetration of direct sunlight are present on windows.

$\sqrt{ } \cdot$ Visual inspection: Mark the circle to the left of the corresponding.
O Yes
No
N/A

L-CS-2) Louvers, baffles or shades: Occupants are able to control the window adjustable Elements (shading devices) designed to control penetration of direct sunlight?

$\sqrt{ } \cdot$ Visual inspection: Mark the circle to the left of the corresponding.
Yes
No
N/A 
L-CS-3) Lighting fixtures blocked: Occupant installed objects which block lighting fixtures, not including intentional shading devices (lamp-shade)

$\checkmark \cdot$ Visual inspection: Mark the circle to the left of the corresponding.
Y Yes
No

L-CS-4/TC-DC-3) Topography: Are there any exterior site features which may cover, protect or block penetration of natural lighting into the space (do NOT include vegetation, e.g. trees, shrubbery).

$\checkmark \cdot$ Visual inspection: Mark the circle to the left of the corresponding.
O Yes
No

\section{ACOUSTICS}

A-SN-1) Sound level: With a decibel meter, measure sound in 3 to 5 different spots (center and near windows or doors) of the room.

$\sqrt{ } \cdot$ Decibel meter: The decibels meter must be in decibels (dBA). Write each measure in the corresponding box.

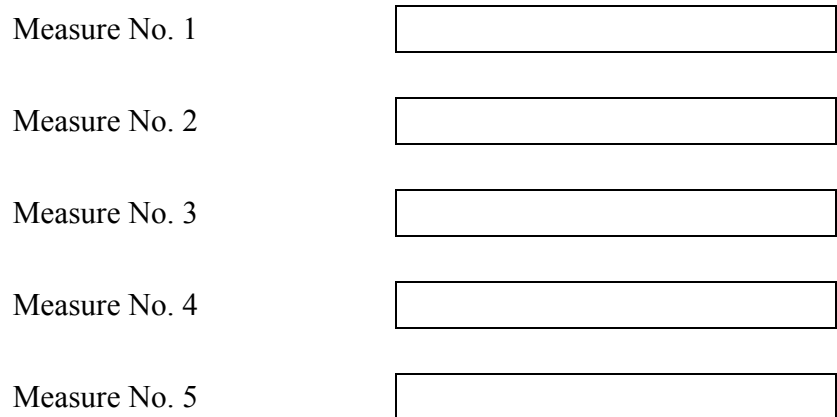

A-SN-2) Sources of noise: Identify systems, spaces and/or functional elements that produce background noise in the room.

$\sqrt{ } \cdot$ Inspection (by hearing): Mark the box to the left of each one of the identified systems, spaces and/or functional elements that produce background noise in the room.

HVAC system
Computers and projectors
Parking, streets
Walkways or hallways
Service rooms
Playground
Gym, cafeteria and recreational spaces
Bell systems
Lighting fixtures

L-SC-1/A-SC-1/TC-DC-2) Form/shape ceiling variation: Does the room have irregular ceiling shape?

$\sqrt{ } \bullet$ Visual Inspection + Review Plans: Mark the circle to the left of "Yes" if the ceiling is slopped or barreled, else Mark "No".
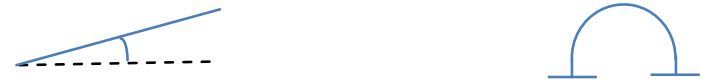
Sloped
Barreled

Yes 


\section{THERMAL COMFORT}

TC-DC-1) Room temperature: With a laser thermometer, measure the temperature in 5 different spots (center and near windows or doors) of the room.

$\sqrt{ } \bullet$ Laser Thermometer: The decibel meter must be in Fahrenheit $\left({ }^{\circ} \mathrm{F}\right)$. Write each measure in the corresponding box.

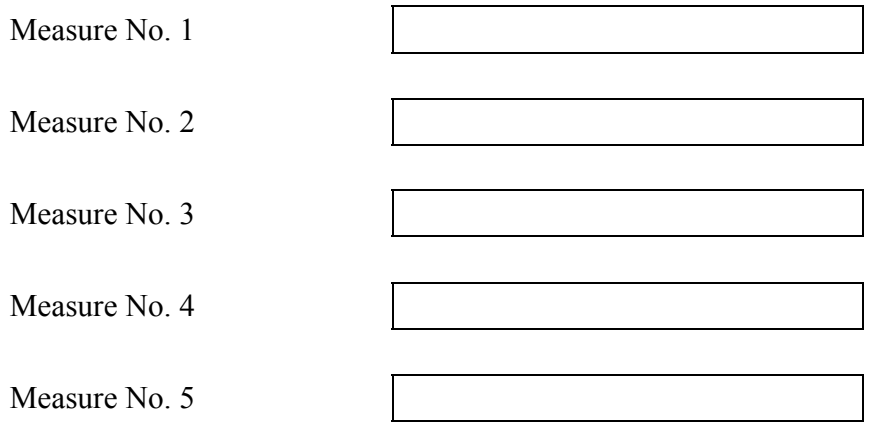

TC-HS-3) Appliances and equipment: Is the temperature $\left({ }^{\circ} \mathrm{F}\right)$ near the following elements within the acceptable comfort range (between $68^{\circ} \mathrm{F}$ to $82^{\circ} \mathrm{F}$ )?

$\sqrt{ } \bullet$ Laser thermometer: Mark the corresponding box (YES or NO) to the right of each equipment.

EQUIPMENT
Lab equipment

A-SC-2a/TC-DC-5) Windows: With a laser meter, measure the total wall area, and total window area (include glass and/or transparent doors and walls) of the room.

$\sqrt{ } \cdot$ Laser meter: Write each measure (in decimals) in the corresponding box. If there are no windows, check the box to the right of N/A (no windows).

$$
\begin{aligned}
& \text { Total wall area } \\
& \text { Total window area } \\
& \text { N/A (no windows) }
\end{aligned}
$$

TC-HS-1a) Thermostat control: The temperature can be adjusted manually by the occupants?

$\checkmark \cdot$ Visual inspection: Mark the circle to the left of the corresponding. If there is no thermostat, mark the circle to the left of "not evident".

$\begin{array}{ll}\bigcirc & \text { Yes } \\ \text { No } & \text { N/A }\end{array}$

TC-DC-5a) Operable windows: The windows can be operated by the room occupants?

$\sqrt{ } \cdot$ Visual inspection + specification: Mark the circle to the left of the corresponding. If there are no windows in the room mark the circle to the left of "N/A".
Y Yes
No
N/A

TC-LCS-3) Shading devices: Physical elements exist (interior or exterior) that control direct sunlight affecting room 
temperature.

$\sqrt{ } \cdot$ Visual inspection: Mark the circle to the left of the corresponding. If there are no windows in the room mark the circle to the left of "N/A".

$\begin{array}{ll}\bigcirc & \text { Yes } \\ \bigcirc & \text { No } \\ & \text { N/A }\end{array}$

TC-LCS-4) Blocking elements (other than shading devices): Any elements which block direct sunlight in the room including vegetation (e.g. trees, shrubbery).

$\sqrt{ } \cdot$ Visual inspection: Mark the circle to the left of the corresponding. If there are no windows in the room mark the circle to the left of "N/A".

$\begin{array}{ll}\bigcirc & \text { Yes } \\ \bigcirc & \text { No } \\ & \text { N/A }\end{array}$

INTERIOR DESIGN

ID-SC-2) Interior Color: Identify the color of interior walls, floors and upholstery in the room.

$\sqrt{ } \cdot$ Visual inspection: Mark the circles that apply.
Pure
Grey and
Colors Other than
White
Beige tones
Whites and Neutrals

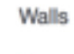

Floors

Upholstery / Furniture

ID-SF-1a) Movable partitions: Do occupants have the ability to vary the room configuration through movable (mobile and/or retractile) walls?

$\sqrt{ } \cdot$ Visual inspection: Mark the circle to the left of the corresponding.
Yes
No

ID-SF-1b) Movable furniture: Can the furniture be rotated and/or moved around the space with the intention to be rearranged in the space?

$\sqrt{ } \cdot$ Visual inspection: Mark the circle to the left of the corresponding.

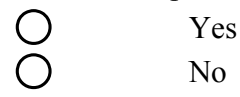

ID-SF-2a) Display surfaces: Does the room have designated areas for displaying student work?

$\sqrt{ } \cdot$ Visual inspection: Mark the circle to the left of the corresponding.
Y Yes
No
N/A (if gym, check this box)

ID-SF-2b) Barriers: Does the room have any structure/object or physical barrier which interferes with line of sight for instruction (e.g.: interior columns)?

$\checkmark \cdot$ Visual inspection: Mark the circle to the left of the corresponding. If the room that is being assessed is a gym, mark the circle to the left of "N/A (if gym, check this box)".
Y Yes
No 
ID-MC-1a) Interior corridor: During class change period, verify how crowded the corridors are.

$\sqrt{ } \cdot$ Visual inspection: Mark the box to the right of the corresponding accordingly with the pictures below and the following descriptions:

(1) comfortable or (2) crowded (see pictures) or (3) unable to observe.
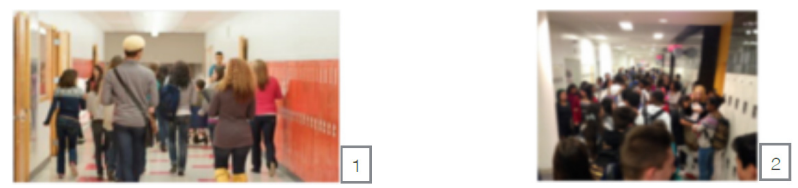

Not peak hours/check this box if unable to observe 3

ID-S-1) Existence of safe room: There is a safe room on the school property

$\sqrt{ } \cdot$ Visual inspection: Mark the circle to the left of the corresponding.
Yes
No

ID-S-2) Visibility

ID-S-2a) Visibility: Identifying path for safe rooms: Clear Identifiable paths to safe rooms are visible upon exiting classroom

$\sqrt{ } \cdot$ Visual inspection: Mark the circle to the left of the corresponding.
Yes
No

ID-S-2b) Visibility: Identifying path for exit areas: Clear Identifiable paths to safe rooms are visible upon exiting classroom

$\sqrt{ } \cdot$ Visual inspection: Mark the circle to the left of the corresponding.
Yes
No

ID-S-2c) Visibility: The interior of the classroom opens to main hallways within 2 turns of the building main entrance.

$\sqrt{ } \cdot$ Visual inspection: Mark the circle to the left of the corresponding.
$O \quad$ Yes
No

ID-S-3) Secured building entry: A secure and operable entry process is used to access the building.

$\sqrt{ } \cdot$ Visual inspection: Mark the circle to the left of the corresponding.
Yes
No

ID-SC-4) Personal and social space: Using a laser meter, measure the distance to from the center of the desks to the (a) front, (b) back, and (c, d) lateral desks.

$\sqrt{ } \cdot$ Laser meter: Write each measure (in decimals) in the corresponding box. If the room is a gym, mark the box to the right of "If gym, check this box".

( a )

( b )

( c )

(d)

c)
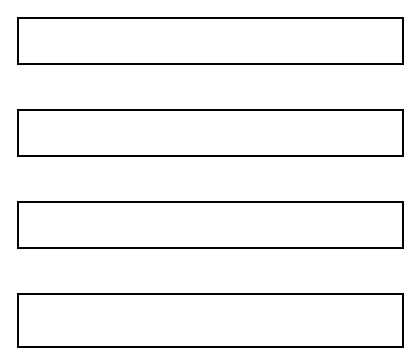

If gym, check this box

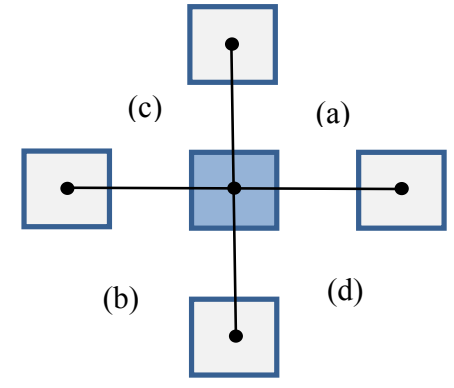




\section{AESTHETICS}

A-V-1) Unrestricted views: Are the windows obstructed to outside views?

$\sqrt{ }$ Visual inspection: Mark the circle to the left of the corresponding.
Yes
No
Partially obstructed
No view

A-V-2) Views of nature: Does the room have views of outdoor natural spaces such as gardens, wildlife, fountains, mountains, or the sky?

$\sqrt{ } \bullet$ Visual inspection: Mark the circle to the left of the corresponding.
Yes

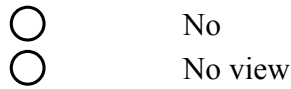

A-V-3) Distant views: With a distance meter, determine if the distance between the window and the closest obstruction is greater than 50 feet (e.g.: walls and buildings)?

$\sqrt{ }$ D Distance meter: Mark the circle to the left of the corresponding.
Y Yes
No
No view

A-IC) Interior physical condition: According to the following pictures and descriptions, assess the physical condition of the room's INTERIOR elements, surfaces and materials.
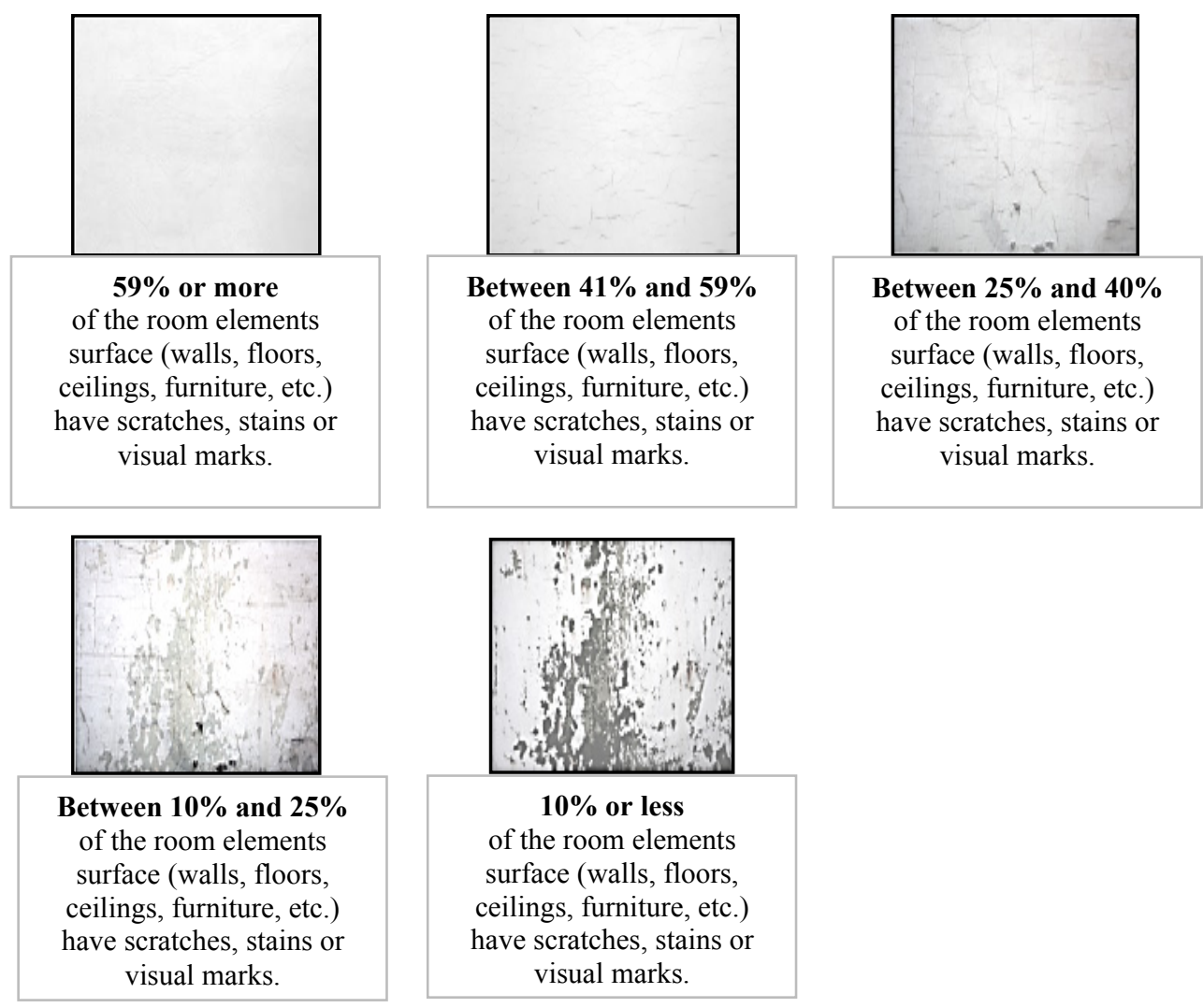
A-IC) Interior physical condition: Base on the previous pictures and descriptions, asses the physical condition of the room's INTERIOR elements, surfaces and materials.

$\sqrt{ } \cdot$ Visual inspection: Mark the corresponding box matching the element assessed and its actual physical condition.

Which percentage (\%) of the surface of the room elements (walls, floors, ceilings, furniture, etc. contain scratches, stains or visual marks.

\section{ELEMENT, SURFACE OR MATERIAL} INSPECTED

\section{CONDITION}

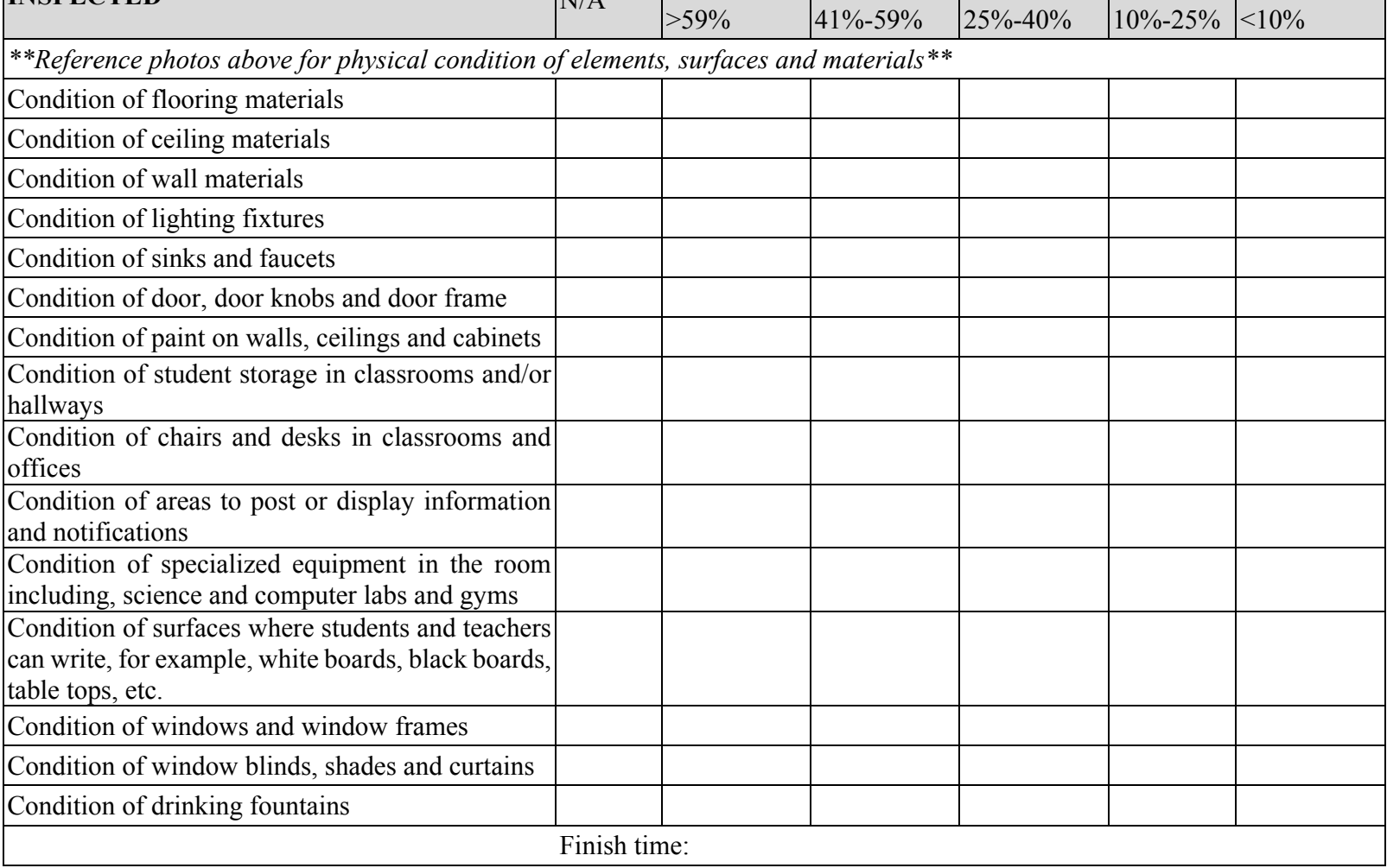

